OPEN ACCESS

Edited by:

Jorge Enrique Gómez Marín University of Quindío, Colombia

Reviewed by:

Elisa Azuara-Liceaga,

Universidad Autónoma de la Ciudad de México, Mexico

César López-Camarillo,

Universidad Autónoma de la Ciudad de México, Mexico

*Correspondence: M. Guadalupe Ortega-Pierres gortega@cinvestav.mx

Specialty section: This article was submitted to

Parasite and Host,

a section of the journal Frontiers in Cellular and Infection

Microbiology

Received: 12 May 2018 Accepted: 18 September 2018

Published: 15 October 2018

Citation:

Argüello-García $R$, de la Vega-Arnaud M, Loredo-Rodríguez IJ, Mejía-Corona AM, Melgarejo-Trejo E, Espinoza-Contreras EA, Fonseca-Liñán R, González-Robles A,

Pérez-Hernández $N$ and Ortega-Pierres MG (2018) Activity of Thioallyl Compounds From Garlic

Against Giardia duodenalis Trophozoites and in Experimental Giardiasis.

Front. Cell. Infect. Microbiol. 8:353. doi: 10.3389/fcimb.2018.00353

\section{Activity of Thioallyl Compounds From Garlic Against Giardia duodenalis Trophozoites and in Experimental Giardiasis}

\author{
Raúl Argüello-García ${ }^{1}$, Mariana de la Vega-Arnaud ${ }^{1}$, Iraís J. Loredo-Rodríguez ${ }^{1}$, \\ Adriana M. Mejía-Corona ${ }^{1}$, Elizabeth Melgarejo-Trejo ${ }^{1}$, Eulogia A. Espinoza-Contreras ${ }^{1}$, \\ Rocío Fonseca-Liñán ${ }^{1}$, Arturo González-Robles ${ }^{2}$, Nury Pérez-Hernández ${ }^{3}$ and \\ M. Guadalupe Ortega-Pierres ${ }^{1 *}$
}

\begin{abstract}
' Departamento de Genética y Biología Molecular, Centro de Investigación y de Estudios Avanzados del Instituto Politécnico Nacional, Mexico City, Mexico, ${ }^{2}$ Departamento de Infectómica y Patogénesis Experimental, Centro de Investigación y de Estudios Avanzados del Instituto Politécnico Nacional, Mexico City, Mexico, ${ }^{3}$ Escuela Nacional de Medicina y Homeopatía, Instituto Politécnico Nacional, Mexico City, Mexico
\end{abstract}

Fresh aqueous extracts (AGEs) and several thioallyl compounds (TACs) from garlic have an important antimicrobial activity that likely involves their interaction with exposed thiol groups at single aminoacids or target proteins. Since these groups are present in Giardia duodenalis trophozoites, in this work we evaluated the anti-giardial activity of AGE and several garlic's TACs. In vitro susceptibility assays showed that AGE affected trophozoite viability initially by a mechanism impairing cell integrity and oxidoreductase activities while diesterase activities were abrogated at higher AGE concentrations. The giardicidal activities of seven TACs were related to the molecular descriptor HOMO (Highest Occupied Molecular Orbital) energy and with their capacity to modify the -SH groups exposed in giardial proteins. Interestingly, the activity of several cysteine proteases in trophozoite lysates was inhibited by representative TACs as well as the cytopathic effect of the virulence factor giardipain-1. Of these, allicin showed the highest anti-giardial activity, the lower $\mathrm{HOMO}$ value, the highest thiol-modifying activity and the greatest inhibition of cysteine proteases. Allicin had a cytolytic mechanism in trophozoites with subsequent impairment of diesterase and oxidoreductase activities in a similar way to AGE. In addition, by electron microscopy a marked destruction of plasma membrane and endomembranes was observed in allicin-treated trophozoites while cytoskeletal elements were not affected. In further flow cytometry analyses pro-apoptotic effects of allicin concomitant to partial cell cycle arrest at G2 phase with the absence of oxidative stress were observed. In experimental infections of gerbils, the intragastric administration of AGE or allicin decreased parasite numbers and eliminated trophozoites in experimentally infected animals, respectively. These data suggest a potential use of TACs from garlic against $G$. duodenalis and in the treatment of giardiasis along with their additional benefits in the host's health.

Keywords: Giardia duodenalis, trophozoite damage, garlic, thioallyl compounds, allicin, giardiasis 


\section{INTRODUCTION}

Giardiasis is the intestinal parasitosis of highest incidence in developed countries with a global distribution of 280 million cases per year. Nearly 200 million people with symptomatic infections have been reported in Asia, Africa and Latin America where some 500,000 new cases per year are reported (Adam, 2001; Lane and Lloyd, 2002; WHO, 2006). Infection initiates when a vertebrate host consumes water or food containing infective cysts of Giardia duodenalis (syn. Giardia lamblia, Giardia intestinalis) and in the acidic gastric environment excystation is induced releasing excyzoites that divide to form trophozoites. These latter adhere to duodenum and jejunum epithelia triggering the pathogenic onset associated to giardiasis. At jejunum-ileum lumen trophozoites are exposed to high bile and low cholesterol concentrations at a slightly alkaline $\mathrm{pH}$ conditions that induce encystation. Cysts are shed in feces where they mature and remain viable for long periods of time until these are ingested by a new host. This infection may be symptomatic with acute signals characterized by diarrhea and abdominal complaints that may lead to malabsorption syndrome eventually associated to chronic outcomes. However, asymptomatic carriers have been found as a major group in hyperendemic areas (Redlinger et al., 2002).

The main strategy for the control of infections caused by G. duodenalis, comprises the use of a variety of antimicrobial drugs including acridines, (quinacrine), aminoglycosides (paromomycin) and most commonly drugs uses are 5nitroheterocyclic compounds [metronidazole (MTZ), furazolidone, and nitazoxanide] and benzimidazoles [albendazole (ABZ) and mebendazole]. Most of these drugs have mild-to-severe secondary effects (revised by Gardner and Hill, 2001). Further, the use of sublethal concentrations of antigiardial drugs in vitro or suboptimal therapy regimes, which include single-dose regimes of benzimidazoles given in communitarian programs to deworm children in endemic localities, may derive into selection of drug resistant parasites and increased incidences of giardiasis (Northrop-Clewes et al., 2001; Argüello-García et al., 2004). Thereby a better knowledge of therapeutic targets in Giardia is needed to develop more effective drugs for the treatment of giardiasis. In this context, compounds derived from natural products such as garlic (Allium sativum L.), may be considered as promising and alternative perspective for treatment of giardiasis (Anthony et al., 2005).

Garlic, a perennial crop common in the human diet, has been used since ancient times in folk medicine of different cultures as a panacea. Likewise aqueous and oil extracts of garlic bulbs provide benefits in the prevention and treatment of gastrointestinal disorders including carcinogenesis and some infections (Ankri and Mirelman, 1999; Anthony et al., 2005; Bhagyalakshmi et al., 2007), however the basis of its effectiveness have not yet been completely unraveled. In this context, there are reports on the anti-tumoral activities of a number of organosulfur compounds contained or derived from garlic. This is most likely due to the modulatory activity of these compounds on carcinogen metabolizing enzymes combined with the pro-apoptotic, antioxidant and radical scavenging properties
(Milner, 2001; Yang et al., 2001; Argüello-García et al., 2010; De Gianni and Fimognari, 2015). Also, garlic compounds were reported to have a direct activity against bacterial, protozoan, fungal and viral pathogens (reviewed by Bhagyalakshmi et al., 2007). Although this broad antimicrobial activity is not readily explained by the aforementioned activities, there is accumulating evidence that organosulfur compounds are able to interact with highly reactive or unshielded thiol moieties of target proteins or aminoacids (e.g., enzymes or cysteine, respectively) forming the corresponding thioallyl adducts $\left(\mathrm{R}-\mathrm{SCH}_{2} \mathrm{CHCH}_{2}\right)$, an event potentially life threatening for the cell. Components from garlic that may be involved on these thiol-disulphide exchange reactions are the thioallyl compounds (TACs) that include S-allyl cysteine (obtained by long-time organic fermentation of whole bulbs in ethanolic solutions), allyl thiosulfinates (e.g., allicin, obtained by crushing o macerating bulbs in water) and some products of allicin decomposition (allyl sulfides and ajoenes) (Lawson and Wang, 1993; Rabinkov et al., 1998; Gallwitz et al., 1999; Gupta and Porter, 2001; Pinto et al., 2006).

Garlic has been shown to have an effect in children suffering from giardiasis when used at 1:20 dilutions of aqueous extract in 2 doses per day for 3 days (Soffar and Mokhtar, 1991) and in vitro studies have shown that whole garlic extract and allyl alcohol have an effect on the physiology of Giardia trophozoites. These include cell surface rigidity, adhesion, flagellar activity, cytoskeletal components, and endomembrane elements (vesicles and vacuoles) while allyl mercaptan (AM, a $\mathrm{TAC}$ ) preferentially induced vesicle distension and cell swelling, possibly related to a primary effect on membrane osmoregulation (Harris et al., 2000). Based on these observations it is likely that several garlic components do have different electivity in G. duodenalis trophozoites, however the mechanisms involved in their giardicidal activity are still undefined. Although this microaerophilic protozoan is devoid of glutathione as major nonprotein thiol, Giardia possesses a plethora of cysteine-rich surface proteins, cysteine-type proteinases and other sulfur-containing intracellular proteins (Ali and Nozaki, 2007) that may be targets of TACs. In this work, we carried out an analysis on the structure-activity relationship (SAR), mode of action and efficacy in experimental giardiasis of representative TACs from garlic.

\section{MATERIALS AND METHODS}

\section{Parasites}

G. duodenalis trophozoites from the WB strain (ATCC \# 30957) were axenically cultured in modified Diamond's TYI-S-33 medium (Keister, 1983) without bile at $37^{\circ} \mathrm{C}$. Cell harvests were carried out by chilling flasks at the log phase of growth reached after $72-96 \mathrm{~h}$ routine subcultures. Detached trophozoites were either directly counted in a haemocytometer or washed 3 times with phosphate buffer saline (PBS) prior to counting and the cell number was adjusted as required in the assays.

\section{Garlic Extracts and Compounds}

Fresh, aqueous garlic extract (AGE) was prepared by crushing peeled, chopped and weighed garlic bulbs (A. sativum L.) in distilled water $(0.1 \mathrm{~g} / \mathrm{mL})$ at $\mathrm{pH} 6.5$ using a mortar. After 
resting for $10 \mathrm{~min}$, homogenate was filtered through a $0.45 \mu \mathrm{M}$ pore size Millipore ${ }^{\mathrm{TM}}$ membrane. The filtrate was recovered and used at the required concentrations. Regarding the garlic components the following compounds were used: alliin (S-allyl cysteine sulphoxide, ALI), diallyl sulfide (DAS) and dipropyl sulfide (DPS) from Fluka Chemika AG (Buchs, Switzerland); diallyl disulphide (DADS), dipropyl disulphide (DPDS), allyl methyl sulfide (AMS) and allyl mercaptan (AM) from Aldrich Chem. Co. (Milwaukee, WI, USA); methyl methanethiosulfonate (MMTS) and sodium p-hydroxymercuribenzoate (pHMB) from Sigma Chem. Co. (St. Louis, MO, USA); S-allyl-L-cysteine (SAC) from TCI (Tokyo Kasei Kogyo Co., Tokyo, Japan) and diallyl trisulfide (DATS) from MP Biomedicals Inc. (Solon, OH, USA). Allicin (diallyl thiosulfinate, ALC) was obtained by oxidation of DADS using the protocol originally reported by Lawson (Lawson, 1996; Argüello-García et al., 2010). In this, $1 \mathrm{~g}$ DADS was dissolved in $5 \mathrm{~mL}$ acetic acid under stirring on an ice bath. Hydrogen peroxide $(1.5 \mathrm{~mL}, 30 \% \mathrm{v} / \mathrm{v})$ was added stepwise and the reaction was allowed to proceed for $30 \mathrm{~min}$. Then, the reaction was kept at $13^{\circ} \mathrm{C}$ for $20 \mathrm{~min}$ then it was placed on an ice bath for $5 \mathrm{~h}$ to minimize the content of remaining DADS. Reaction was stopped by adding $15 \mathrm{~mL}$ distilled water at $\mathrm{pH} 6.5$ and it was extracted with $30 \mathrm{~mL}$ dichloromethane. Acetic acid was removed by 5 extractions with $5 \%(\mathrm{w} / \mathrm{v})$ sodium bicarbonate $(20 \mathrm{~mL}$ each) then by 3 extractions with distilled water $(20 \mathrm{~mL}$ each). The solvent was left to evaporate until yellowish oil (ALC, yield of $\sim 600-800 \mu \mathrm{L}$ per assay) was obtained. For stabilization and storage of ALC, the oily product was resuspended in water at $1.5 \%(\mathrm{w} / \mathrm{v})$ and kept in $1 \mathrm{~mL}$ aliquots at $-70^{\circ} \mathrm{C}$ until analyzed and used. Under these conditions, ALC retained its full activity for up to 6 months. The identification of ALC was performed by Nuclear Magnetic Resonance $\left({ }^{13} \mathrm{C}\right.$ - and ${ }^{1} \mathrm{H}$-spectra) using a Jeol Eclipse ${ }^{\mathrm{TM}}$ spectrometer with deuterated carbon trichloride $\left(\mathrm{CDCl}_{3}\right)$ as solvent and tetramethylsilane as reference solution. Chemical shifts were recorded in ppm at $300 \mathrm{MHz}$ in a Brucker system. Purity of ALC was determined by High Performance Liquid Chromatography (Waters model 996 coupled to a pump Waters model 600) using $4.6 \times 250 \mathrm{~mm}$ Spherisorb ${ }^{\mathrm{TM}}$ columns (10 $\mu \mathrm{M}$ particle size), mobile phase $30 \%$ methanol:70\% water, flow rate $0.4 \mathrm{~mL} / \mathrm{min}$ and UV detection at $254 \mathrm{~nm}$, rendering an average time retention of $3.61 \mathrm{~min}$ and a mean purity of $90-92 \%$ for synthetic allicin.

\section{In vitro Susceptibility Assays}

When complete TYI-S-33 medium (final cysteine concentration $=12.4 \mathrm{mM}$ ) was used, it was no older than 10 days to avoid cysteine oxidation. In these assays, $1 \times 10^{6}$ trophozoites were exposed to increasing concentrations of AGE or TACs for $24 \mathrm{~h}$ at $37^{\circ} \mathrm{C}$ in $4.5 \mathrm{~mL}$ screw-capped vials. Positive controls included trophozoites treated with metronidazole at 3.0 and $5.9 \mu \mathrm{M}$ (corresponding to its $\mathrm{IC}_{50}$ and MLC; ArgüelloGarcía et al., 2004) and as a negative control for the vehicle, $20 \mu \mathrm{L}$ distilled water, $\mathrm{pH} 6.5$ were included in all experiments to discard significant variabilities in standard drug susceptibility of the WB strain used in this study. Parasites were harvested and counted and trophozoite's viability was determined by physiological methods to determine the growth capacity of trophozoites after drug exposure (subculture in liquid medium SCLM)] or trophozoite and membrane integrity [direct cell count (DCC) and trypan blue exclusion (TBE), respectively]. Also, enzyme activity-based methods were used and these included fluorescein diacetate-propidium iodide staining (FDA-PI) that relies on the ability of cellular esterases in living cells to hydrolyse FDA into fluorescein while PI form complexes with nucleic acids of dead cells (Breeuwer et al., 1995); the 3-(4,5-dimethyl-2-thiazolyl)2,5-diphenyl-2-H-tetrazolium bromide (MTT) reduction assay that is based on the crystallyzation of the formazan derivative of MTT in living cells by the action of cellular oxidoreductases (NAD $(\mathrm{P}) \mathrm{H}$-dependent dehydrogenases, reductases) (Liu et al., 1997). All these protocols have been described elsewhere (Argüello-García et al., 2004) except that DCC values were calculated from total cell numbers of compound-exposed trophozoites divided by the initial trophozoites' inoculum $(1 \times$ $10^{6}$ ) and TBE was performed by incubating PBS-washed parasites in a trypan blue solution $(0.4 \%[\mathrm{w} / \mathrm{v}]$ final concentration) for $5 \mathrm{~min}$ at room temperature followed by microscopic count of "stained" (non-viable) parasites. As reference, the "gold standard" method (SCLM) consisted in the back growth of $1 \times$ $10^{5}$ parasites for $48 \mathrm{~h}$ at $37^{\circ} \mathrm{C}$ after exposure to compounds and the interpolation of cell counts into a standard growth curve run in parallel using increasing number of parasites $(5,000-250,000)$ non exposed to any drug.

In each method, the inhibitory concentration at 50\% ( $\left.\mathrm{IC}_{50}\right)$ and the minimal lethal concentration (MLC) corresponding to the lower concentration of compound that caused mortality in all cells were calculated using the concentration-viability curves in which the minimal-square method was used. Statistical significance between the data obtained in two or more experiments was determined by paired, two-tailed $t$-Student's test (Microsoft Excel $^{\mathrm{TM}}$ ).

\section{Electron Microscopy Studies}

Trophozoites were exposed to TACs in two ways: under long ( $24 \mathrm{~h}$, standard toxicity) and short ( $3 \mathrm{~h}$, acute toxicity) incubations at $37^{\circ} \mathrm{C}$ using concentrations corresponding to the experimental MLC (as determined at $24 \mathrm{~h}$ ) and twofold the MLC, respectively. For scanning electron microscopy, PBSwashed parasites were fixed with $2.5 \%$ glutaraldehyde in $0.1 \mathrm{M}$ sodium cacodylate buffer, $\mathrm{pH} 7.2$, dehydrated under increasing concentrations of ethanol, critical-point dried using a Samdri apparatus, gold coated in an ion sputtering device (JEOLJFC-1100), and examined with a JEOL 35-C scanning electron microscope. In transmission electron microscopy (TEM) studies, washed cells were fixed with $2.5 \%$ glutaraldehyde and postfixed with $1 \%$ osmium tetroxide in cacodylate buffer. Following sequential dehydration in ethanol, samples were embedded with epoxy resins. Thin sections were observed in a JEOL 100-SX transmission electron microscope.

\section{SAR Analyses}

The values of four electronic and two molecular transport (absorption prediction) descriptors have been previously determined for most TAC used herein (see Table 2 in ArgüelloGarcía et al., 2010). Briefly, the chemical structures of the 
ten compounds were constructed using Chemdraw Ultra 8.0 software (Cambridge soft Corp. Cambridge, MA, USA) and imported into SPARTAN'04 package (Wave function Inc. Irvine, CA, USA). The $a b$ initio approach was used in this software to minimize structures and obtain equilibrium geometry in vacuo using the semi-empirical AM1 module. Thus, the minimal energy conformations (Boltzmann conformers) of each compound were obtained by default parameters in order to determine values for electronic properties that included HOMO (highest occupied molecular orbital, $\left.E_{H O M O}\right)$ and LUMO (lowest unoccupied molecular orbital, $E_{L U M O}$ ) eigen values, dipole moment (Debye) and total energy $\left(E_{T O T A L}\right)$. Regarding the two descriptors related to absorption prediction, the octanol/water partition coefficient $\left(\log P_{\text {oct }}\right)$ values were retrieved from other studies while the molecular polar surface area (PSA) was calculated following the fragment-based contribution procedure. The relationship between the values of each of these molecular descriptors and the giardicidal activity (expressed as MLC values) were determined by multiple regression analysis (MLR) using the 16.0 .18 version of Statgraphics Centurion XVI software.

\section{Thiol-Modifying Activity of TACs}

The technique reported by Lawson and Wang (1993) was followed. In these assays trophozoites were collected from $60 \mathrm{~mL}$ flasks, washed 3 times with PBS and resuspended in $500 \mu \mathrm{L}$ PBS containing a 1:12.5 dilution of a commercial mixture of protease inhibitors (Complete ${ }^{\mathrm{TM}}$, Roche Diagnostics $\mathrm{GmbH}$, Indianapolis, IN, USA) and lysed by sonication at 12 microns $/ 60 \%$ amplitude (Ultrasonic apparatus Sonic UVX1130PB). Soluble proteins were recovered by centrifugation at $15,400 \times \mathrm{g}$ for $30 \mathrm{~min}$ at $4^{\circ} \mathrm{C}$ and protein concentration was determined by the Bradford technique. These samples were adjusted to a concentration of $1 \mathrm{mg} / \mathrm{mL}$. Reactions were carried out in $1.5 \mathrm{~mL}$ microcentrifuge tubes with a mixture of 100 $\mu \mathrm{g}$ protein $(100 \mu \mathrm{L})$ and $\mathrm{NaH}_{2} \mathrm{PO}_{4} 45 \mathrm{mM}$ pH $7.0 \mathrm{mM}(800$ $\mu \mathrm{L})$ to which increasing volumes of TACs stocks or a positive control with the thiol derivatizing agent MMTS prepared at $50 \mathrm{mM}$ in the same buffer, were added and total volume was adjusted to $1 \mathrm{~mL}$. After incubation for $10 \mathrm{~min}$ at $37^{\circ} \mathrm{C}, 100 \mu \mathrm{L}$ of $1.5 \mathrm{mM}$ dithionitrobenzoic acid (DTNB, Ellman's reagent) were added to each tube and following incubation for $10 \mathrm{~min}$ at room temperature the absorbances (yellow solutions) were recorded at $412 \mathrm{~nm}$ (Smart Spec $3000^{\mathrm{TM}}$, Bio-Rad, Hercules, CA, USA). A calibration curve was obtained using increasing volumes $(0-100 \mu \mathrm{L})$ of $15.5 \mathrm{mM}$ cysteine instead protein extracts and the maximal blocking concentration (MBC) corresponding to a complete absence of thiol-DTNB complexes produced by TACs were calculated using the least-square method (Microsoft Excel $\left.^{\mathrm{TM}}\right)$.

\section{Proteolytic Activity Assays}

Trophozoite lysates were prepared as mentioned above except that cell lysis was carried out by sonication in $1.5 \mathrm{~mL}$ microcentrifuge tubes under ice bath using eight 15-s pulses at $80 \%$ amplitude with resting periods of $30 \mathrm{~s}$ (Ultrasonic Processor mod. CV19). Protein concentration was adjusted to $2 \mathrm{mg} / \mathrm{mL}$ and aliquoted in $25 \mu \mathrm{L}$ fractions that were incubated for $30 \mathrm{~min}$ room temperature with 2-5 $\mu \mathrm{L}$ stock solutions of representative TACs (ALC, DADS, and AM). The reaction mixtures were diluted in Laemmli's sample buffer, loaded in wells of $10 \%$ acrylamide- $02 \%$ gelatin slab gels and these were electrophoretically analyzed using $80 \mathrm{~V} / 4^{\circ} \mathrm{C}$. After this, gels were incubated in a solution of triton X-100 2.5\% (v/v) in water for $1 \mathrm{~h}$ and washed 3 times with distilled water. Bands with proteolytic activity were detected as follows: gels were incubated in acetate buffer pH 5.5 with $1 \mathrm{mM}$ DTT for $16 \mathrm{~h}$ at $37^{\circ} \mathrm{C}$ under constant stirring, washed 3 times with distilled water and stained with Coomassie blue (BioRad) for $2 \mathrm{~h}$ at $37^{\circ} \mathrm{C}$ under constant stirring. Finally, gels were washed with distilled water and incubated with a solution of $5 \%$ acetic acid $/ 40 \%$ methanol (v/v). Gel images were documented with a UVP High Performance Ultraviolet Transilluminator and software Launch DocItLS.

\section{Effect of Representative TACs as Possible Inhibitors of the Cytolytic Effect of Giardipain-1 on IEC6 Cell Monolayers}

Based on the inhibitory concentrations of TACs over the activity displayed by the $\approx 25-\mathrm{kDa}$ sized band containing giardipain- 1 in zymograms, this protease purified by affinity chromartography from trophozoite lysates at a cytotoxic concentration $(16 \mu \mathrm{g} / \mathrm{mL}$; Ortega-Pierres et al., 2018) was pre-incubated for $30 \mathrm{~min}$ at room temperature in $200 \mu \mathrm{L}$ DMEM medium alone or containing ALC (5.3 mM), DADS (275 mM), AM (514 mM), or E64 $(20 \mu \mathrm{M})$. Additional assays were carried out using the MLCs of TACs (without giardipain-1) previously obtained in trophozoite cultures to monitor their toxicity. These solutions were added to monolayers of the intestinal cell line IEC6 grown in $1 \mathrm{~cm}^{2}$-microwells and incubated for $100 \mathrm{~min}$ at $37^{\circ} \mathrm{C}$. After incubation, supernatants were discarded and monolayers were fixed with $2 \%$ paraformaldehyde in PBS. The effects of TACs and E64 on the cytolytic effect of giardipain-1 were evaluated by light microscopy using Nomarski optics (Axioskop 40, Zeiss).

\section{Flow Cytometry Analyses}

The identification and quantitative determinations of trophozoites were carried out as follows: (a) apoptosis or necrosis were determined using anti-annexin V-fluorescein isothiocyanate (FITC) antibodies or PI as respective markers, (b) oxidative stress was determined by formation of reactive oxygen species (ROS) with the fluorescent ROS-complexing agent 5-(and 6)-carboxy 2'7'-dichlorodihydrofluorescein diacetate $\left(\mathrm{H}_{2} \mathrm{DCFDA}\right)$, and (c) determination of trophozoites cell cycle stages (G1, S, G2, and G2/M) after exposure to ALC or to a control drug (albendazole, ABZ) was carried out as previously described (Martínez-Espinosa et al., 2015). In all these assays 20,000 cells per sample were recorded.

\section{Efficacy of Age and TACs in Experimental Giardiasis}

Mongolian gerbils (Meriones unguiculatus) used in this study were kept at CINVESTAV's bioterium facilities under regulated conditions of temperature, humidity, and filtered air. Animals 
were fed ad libitum with rodent pellets (Purina ${ }^{\mathrm{TM}}$ ) and water and monitored daily. The management of gerbils was performed according to the Mexican official norm NOM-062-ZOO-1999 for the production, care and use of laboratory animals (UPEALCINVESTAV). Eighty male Mongolian gerbils ( $M$. unguiculatus) 6-10 weeks old, weighted 45-60 g and sentinel-checked gerbils free of intestinal parasites were kept in individual cages and distributed in 12 groups of 6 animals per treatment and experimental infections were performed as described elsewhere (Argüello-García and Ortega-Pierres, 1997). In brief, animals were inoculated intragastrically with $1 \times 10^{6} \mathrm{G}$. duodenalis trophozoites in $500 \mu \mathrm{l}$ sterile PBS per os using gavage under ether anesthesia. Control animals received $500 \mu \mathrm{l}$ sterile PBS each. At day 10 post-infection (p.i.), gerbils were treated with AGE at single doses of $385,770,1,155$, and $1,550 \mathrm{mg} / \mathrm{kg}$ or two doses of $770 \mathrm{mg} / \mathrm{kg}$ (days 10 and 11 p.i.) or a selected TAC (here ALC at $35,70,138$, or $276 \mathrm{mg} / \mathrm{kg}$ at single dose). As additional control, one group of animals received MTZ $(38.4 \mathrm{mg} / \mathrm{kg}$ at single or double dose). Only the higher, single doses of AGE $(1.55 \mathrm{~g} / \mathrm{kg})$ and ALC $(276 \mathrm{mg} / \mathrm{kg})$ caused a noticeable irritation in intestinal epithelium as assessed by surgical examination of treated, non-infected animals ( $n=1$ per single dose). Treatment efficacy was evaluated by determining the presence or absence of trophozoites in intestinal contents of control and treated gerbils at day 13 post-infection. For this, gerbils were euthanized by an intraperitoneal injection of pentobarbital at a dose of $150 \mathrm{mg} / \mathrm{kg}$ to minimize stress and to reduce suffering, then a $10 \mathrm{~cm}$-long section of intestine (from stomach ending, equivalent to nearly the entire small intestine) was excised after laparotomy, and it was longitudinally opened and rinsed in $20 \mathrm{~mL}$ PBS at $4^{\circ} \mathrm{C}$ for 20 min under shaking $\left(720 \mathrm{rpm}\right.$, Heidolph ${ }^{\mathrm{TM}}$ rotatory shaker) to determine trophozoites number after parasite detachment from microvilli. Supernatant was collected and centrifuged at $750 \times$ $\mathrm{g}$ for $10 \mathrm{~min}$ at $4^{\circ} \mathrm{C}$, cell pellet was resuspended in $1 \mathrm{~mL}$ PBS and trophozoites were counted using a haemocytometer. Gerbils were scored as cured if no trophozoites were recovered from infected animals.

\section{Molecular Modeling and Docking Studies}

The three-dimensional protein structure of giardipain-1 was obtained from the sequence of GL50803_14019 deposited in GiardiaDB using the Swiss Model server (https://swissmodel. expasy.org/). To predict the ability of garlic TACs (ALC, DADS, and $\mathrm{AM}$ ) as possible inhibitors of the protease activity of giardipain-1 by interaction with its catalytic moiety, in silico approaches of molecular docking were performed using the Swiss Dock web service (http://swissdock.ch). This platform delivers a set of 256 viable positions between rigid target (mGiardipain-1) and one flexible ligand (TACs) that are input in $\mathrm{PDB}$ and MOL2 formats, respectively. Of these predictions, only those involving a likely interaction of inhibitor with the catalytic Cys27 in giardipain-1 were selected and from these, the most favored docking corresponded to the lowest (i.e., negative value) Gibbs free energy $(\Delta G)$. In these analyses, the crystal structure of human Cathepsin B (PDB ID: $2 \mathrm{PBH}$ ) was used as structure of reference. All structures and predictions obtained from Swiss Model, SwissDock and
ZINC archives of TACs (www:// http://zinc.docking.org/) were visualized and edited using the UCSF chimera package $v$. 1.10 .1

\section{Statistical Analyses}

In all experiments involving concentration-response curves the values obtained were adjusted with the least-square method to linearize calibration curves (Microsoft Excel 2010 ${ }^{\mathrm{TM}}$ ) and differences in mean \pm SD values between two or more groups were assessed by the $t$-student test at a significance of $P<0.05$.

\section{RESULTS}

\section{Efficacy and Mode of Action of Age Against Giardia Trophozoites}

In all drug susceptibility assays, positive controls with 3.0 and $5.9 \mu \mathrm{M}$ metronidazole inhibited trophozoite growth by $45-55 \%$ and more than 95\%, respectively, as expected while distilled water $\mathrm{pH} 6.5$ did not affect parasite's growth. In a first set of experiments, fresh AGEs were prepared and added at increasing concentrations to trophozoite cultures to assess parasite's viability by physiological (SCLM and DCC) and enzyme activity-based (FDA-PI and MTT) methods. It is worth mention that garlic components in the $0-400 \mu \mathrm{g} / \mathrm{mL}$ range produced a progressive decay (up to $>80 \%$ ) in the number of trophozoites with ability to either re-grow, maintain cellular integrity or reduce MTT; however even at $400 \mu \mathrm{g} / \mathrm{mL}$ AGE more than $60 \%$ of remaining cells were still positive for FDA-PI staining (Figure 1A). IC $_{50}$ and MLC calculations confirmed a similar sensitivity of SCLM, DCC, and MTT assays and a significantly lower sensitivity of the FDA-PI method (Figure 1B), indicating that components from garlic extracts induce primary effects on trophozoite integrity concomitant to loss of oxidoreductase activities and a delayed detriment of esterase activities.

\section{SAR of TACs}

To evaluate the giardicidal activity of the six garlic's TACs initially included and its relation to the compound structure the SCLM method was chosen considering its aforementioned higher sensitivity and from reports using well-known antigiardial compounds that include 5-nitroimidazoles and bencimidazoles (Argüello-García et al., 2004, 2009). These TACs have defined modifications in their chemical structure mainly involving increasing hydrocarbon chains with carbon-carbon double bonds and additions of sulfur and/or oxygen atoms or even $\alpha$ aminoacidic groups thus rendering $\mathrm{AM}$ as the simplest and SAC as the most complex TAC evaluated herein. As shown in Table 1 the thioallyl group displayed in bold in each chemical formula and comparing experimental MLC values, the giardicidal efficacy of AM was drastically lowered (3.06 vs. $74.28 \mathrm{mM}$ ) by replacing the sulfur-attached Hydrogen by a methyl group as in AMS; however the replacement of this Hydrogen by an allyl group as in DAS partially recovers the efficacy in one order of magnitude $(23.71 \mathrm{mM})$ below to that of AM. Interestingly the further addition of a second sulfur atom, as in DADS, recovers fully the efficacy to a comparable level of that displayed by AM $(2.66 \mathrm{mM})$. Further the addition of a 


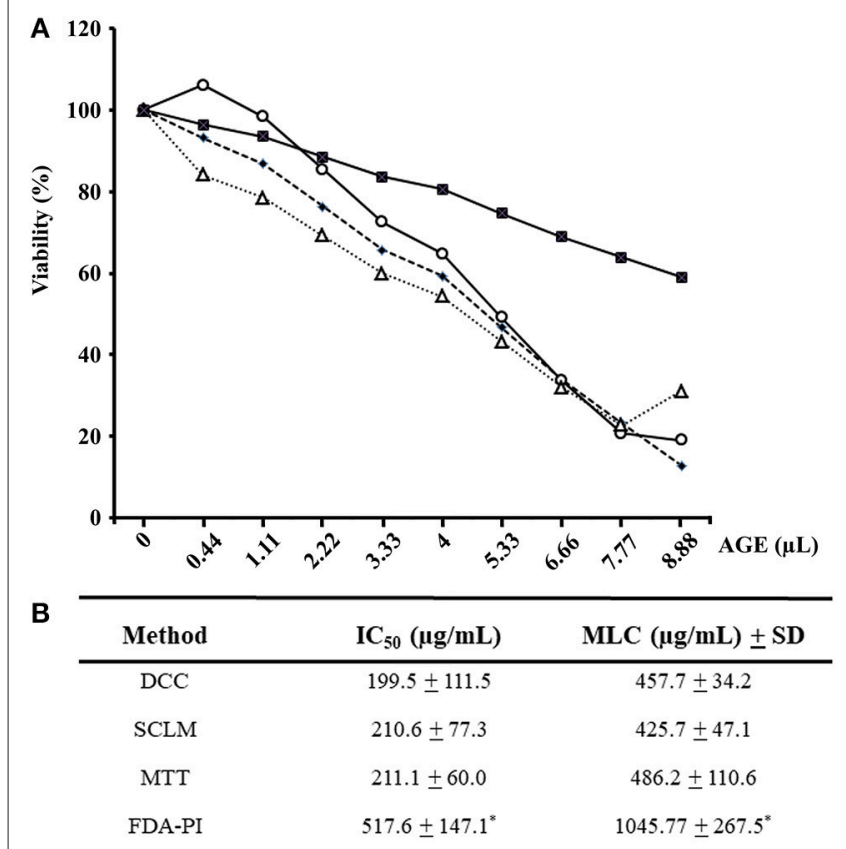

FIGURE 1 | Evaluation of susceptibility of G. duodenalis trophozoites to aqueous garlic extract (AGE) using four methods. (A) Parasites $\left(1 \times 10^{6}\right)$ were exposed to increasing quantities of $200 \mu \mathrm{g} / \mathrm{mL}$ AGE for $24 \mathrm{~h}$ and cellular viability was determined by four methods: subculture in liquid medium (open circles), FDA-PI staining (filled squares), direct cell count (filled diamonds), and MTT reduction (open triangles). Values correspond to results from three independent experiments. (B) The values of the inhibitory concentrations at $50 \%\left(\mathrm{IC}_{50}\right)$ and $100 \%$ (MLC) were calculated by the least square method. *Significantly higher than any of the other methods at $P<0.05$.

sulfur-attached oxygen atom, as displayed in ALC increased the giardicidal activity to sub-milimolar concentrations $(0.6 \mathrm{mM})$ being ALC (allicin or diallyl thiosulfinate) the most effective TACs tested. In contrast, the presence of one $\alpha$-amino carboxylic group (cysteine) in SAC decreased the efficacy of TACs to similar levels as that of AMS (69.1 vs. $74.28 \mathrm{mM})$. These assays indicated the importance of the dithiol moiety (-SS-) to potentiate the activity of TACs against $G$. duodenalis trophozoites.

In further analysis in which the activity of TACs were compared, an in silico approach based on MLR was used to determine if some of the four electronic $\left(E_{T O T A L} . E_{H O M O}, E_{L U M O}\right.$, dipole) and two molecular transport ( $\log \mathrm{P}_{\text {oct }}$, TPSA) descriptors calculated for these compounds (Supplementary Table 1) could be directly related to the giardicidal efficacy observed. In these analyses an additional TAC, diallyl trisulphide (DATS), was included as a "test" compound to evaluate the predictive value of the best structure-activity model raised. After these analyses, the molecular descriptor $E_{H O M O}$ was the unique parameter associated to MLCs of the six TACs used as "drivers" to standardize the regression model. This latter rendered the lower variance $(S=0.177)$ and the highest regression coefficient $(R=0.9827)$ that were useful for this purpose (Figure 2). When the $E_{H O M O}$ value calculated for DATS $(-209.33 \mathrm{kcal} / \mathrm{mol})$ was
TABLE 1 | Experimental MLC values of six TACs against G. duodenalis trophozoites determined by SCLM.

\begin{tabular}{|c|c|c|c|}
\hline $\begin{array}{l}\text { Thioallyl } \\
\text { compound }\end{array}$ & Chemical formula & $\mathrm{IC}_{50}(\mathrm{mM}) \pm \mathrm{SD}$ & $M L C(m M) \pm S D$ \\
\hline $\begin{array}{l}\text { Allyl Mercaptan } \\
\text { (AM) }\end{array}$ & $\mathrm{H}_{2} \mathrm{C}=\mathrm{CH}-\mathrm{CH}_{2}-\mathrm{SH}$ & $0.83 \pm 0.2$ & $3.06 \pm 0.7$ \\
\hline $\begin{array}{l}\text { Allyl Methyl } \\
\text { Sulfide (AMS) }\end{array}$ & $\mathrm{H}_{2} \mathbf{C}=\mathrm{CH}-\mathrm{CH}_{2}-\mathrm{S}-\mathrm{CH}_{3}$ & $40.3 \pm 3.5$ & $74.28 \pm 12.3$ \\
\hline $\begin{array}{l}\text { Diallyl Sulfide } \\
\text { (DAS) }\end{array}$ & $\begin{array}{l}\mathbf{H}_{\mathbf{2}} \mathbf{C}=\mathbf{C H}-\mathbf{C H}_{\mathbf{2}}-\mathbf{S}- \\
\mathrm{CH}_{2}-\mathrm{CH}=\mathrm{CH}_{2}\end{array}$ & $14.5 \pm 2.3$ & $23.71 \pm 6.0$ \\
\hline $\begin{array}{l}\text { Diallyl Disulfide } \\
\text { (DADS) }\end{array}$ & $\begin{array}{l}\mathbf{H}_{\mathbf{2}} \mathbf{C}=\mathbf{C H}-\mathbf{C H}_{\mathbf{2}} \text {-S-S- } \\
\mathrm{CH}_{2}-\mathrm{CH}=\mathrm{CH}_{2}\end{array}$ & $1.4 \pm 0.6$ & $2.66 \pm 0.8$ \\
\hline Allicin (ALC) & $\begin{array}{l}\mathbf{H}_{\mathbf{2}} \mathbf{C}=\mathbf{C H}-\mathbf{C H}_{\mathbf{2}}-\mathbf{S}-\mathrm{S}(\mathrm{O}) \\
-\mathrm{CH}_{2}-\mathrm{CH}=\mathrm{CH}_{2}\end{array}$ & $0.32 \pm 0.02$ & $0.60 \pm 0.1$ \\
\hline $\begin{array}{l}\text { S-Allyl Cysteine } \\
\text { (SAC) }\end{array}$ & $\begin{array}{l}\mathbf{H}_{\mathbf{2}} \mathbf{C}=\mathbf{C H}-\mathbf{C H} \mathbf{-}-\mathbf{S}- \\
\mathrm{CH}_{2}\left(\mathrm{NH}_{2}\right)-\mathrm{COOH}\end{array}$ & $40.82 \pm 6.3$ & $69.10 \pm 13.1$ \\
\hline
\end{tabular}

interpolated in this model a MLC $=1.41 \mathrm{mM}$ was predicted. This value was closer to the experimental MLC $=1.35 \pm$ $0.18 \mathrm{mM}$ that was determined independently for this compound. Thus based on this approach we concluded that $E_{H O M O}$ is a useful tool to predict the giardicidal activity of garlic's TACs.

\section{Differential Thiol-Disulphide Exchange Capacity of TACs}

Since TACs could modify thiol groups exposed in G. duodenalis trophozoite proteins into di-(thioallyl) derivatives thus hampering the further derivatization of these groups by DTNB, the blocking capacity of seven TACs was evaluated using parasite's total soluble extracts. The data obtained were in general compatible with their already known giardicidal activity, this is ALC was the most potent thiol-modifying compound tested $(\mathrm{MBC}=93.8 \mathrm{mmol} / \mathrm{mg}$ protein) followed by DATS and DADS with MECs slightly higher to $200 \mathrm{mmol} / \mathrm{mg}$. DAS had an intermediate efficacy (351.3 mmol/mg) and AMS and SAC exhibited a much lower efficacy (845.9 and 1260.9 $\mathrm{mmol} / \mathrm{mg}$, respectively) (Figure 3). Interestingly AM, in spite of its high giardicidal activity, it did not react with parasite extracts as noted by the increasing absorbance when higher concentrations of this compound were added and instead it formed complexes with DTNB. Indeed, the presence of increasing sulfur atoms and sulfur-attached oxygen influenced the higher efficacy of TACs to derivatize thiol groups exposed in giardial proteins.

\section{Differential Inhibition of Trophozoite's Proteolytic Activities by Garlic TACs}

Considering the thiol-modifying activity of TACs on trophozoite protein extracts, three representative compounds showing high (ALC), intermediate (DADS), and low (AM) activities were chosen to evaluate their inhibitory effect on cysteine protease activities in trophozoite lysates. Zymogram analysis showed that lysates displayed several bands of proteolysis (mostly between 25 and $110 \mathrm{kDa}$; Figure 4A) of which bands of 75, 60, and 25 


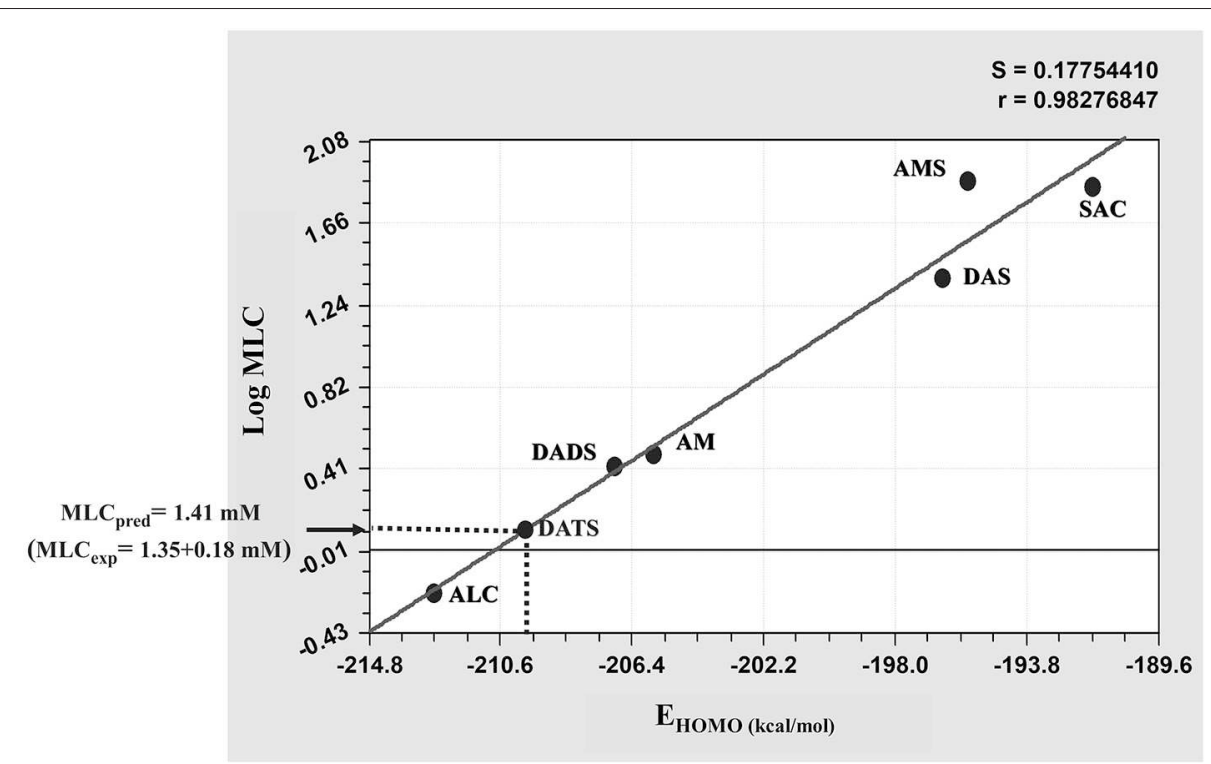

FIGURE 2 | Linear regression model for the MLC-E $E_{H O M O}$ relationship of thioallyl compounds (TACs). The values of giardicidal activity (MLC) and the electronic descriptor $\mathrm{E}_{\mathrm{HOMO}}$ of the six TACs included as "drivers" were processed by multiple linear regression and the value of $\mathrm{E}_{\mathrm{HOMO}}$ calculated for the "test" compound diallyl trisulfide (DATS) was interpolated in the model (dotted line) to predict the MLC of this compound and to compare it with its experimetal MLC. Abbreviations of compound names are as indicated in section Materials and Methods.

$\mathrm{kDa}$ were the most prominent. Some of these activities $(110,60$, 75 , and $25 \mathrm{kDa}$ ) were strongly inhibited by $3.5 \mathrm{mM}$ ALC while DADS at a much higher concentration $(275 \mathrm{mM})$ could diminish similar activities except for the one at $60 \mathrm{kDa}$. Intriguingly AM produced a significant increase of activity in bands of 75 , 60 , and $25 \mathrm{kDa}$ though this might reflect its lack of reactivity toward protein - $\mathrm{SH}$ groups and its "cooperative" activity with DTT. As expected, a full inhibition of all proteolytic bands was observed with the unspecific thiol-active inhibitor $\mathrm{pHMB}$ at $10 \mathrm{mM}$. On the other hand the typical cathepsin B protease inhibitor E64 displayed a selective inhibition on the $25 \mathrm{kDa}$ band that contains the processed form of the cathepsin B-like protease named as giardipain-1 (Ortega-Pierres et al., 2018). By molecular modeling and docking approaches, the higher inhibitory activity of ALC toward proteases like giardipain-1 could be at least partially explained by the predicted ability of its Oxygen atom to form an electron bridge with the Hydrogen G3 of the catalytic Cys26 (Figure 4B) thereby interfering with protease activity. This is reinforced by the similar entropy values predicted for these TACs $\left(\Delta \mathrm{G}_{\mathrm{ALC}}=-5.561 \mathrm{kCal} / \mathrm{mol}\right.$; $\left.\Delta \mathrm{G}_{\mathrm{DADS}}=-6.093 \mathrm{kCal} / \mathrm{mol} ; \Delta \mathrm{G}_{\mathrm{AM}}=-5.554 \mathrm{kCal} / \mathrm{Mol}\right)$. Taken together, these data are concurrent with the notion that garlic TACs target several types of cysteine proteases in G. duodenalis trophozoites.

\section{Inhibition of Cytopathic Effects of mGiardipain-1 by Representative Garlic TACs}

Once the concentrations of ALC, DADS and E64 used in zymograms were shown to inhibit a specific cysteine protease of $G$. duodenalis trophozoites, namely giardipain-1 $(\approx 25 \mathrm{kDa})$, next it was assessed if these compounds could also block the already reported cytopathic effects of giardipain-1 as are shrinkage, detachment from surface, rounding and/or profuse vacuolisation (Ortega-Pierres et al., 2018). As shown in Figure 5, giardipain-1 causes a strong destruction of monolayers beginning with cell shrinkage and profuse blebbing (arrows) and the subsequent appearance of zones with absence of cells reflecting extensive destruction (asterisks) that are consistent with the pro-apoptotic damage reported for this secreted cysteine protease (Ortega-Pierres et al., 2018). However, the pre-incubation of giardipain-1 with ALC and AM noticeably blocked these effects while DADS reduced the frequency of cells displaying apoptotic damage. In general, these observations support a correlation between the inhibitory ability of garlic TACs on the proteolytic activity of giardipain-1 and the damage blockade exerted by these compounds. As expected, the potent cathepsin B inhibitor E64 efficiently inhibited the giardipain-1 induced damage in IEC6 cell monolayers. Of interest, with the exception of DADS concentration used in zymography analyses $(275 \mathrm{mM})$ that affected some cells, none concentrations of TACs tested either at protease-inhibiting level or at MLCs that kill trophozoites in culture, were harmful to cell monolayers (Supplementary Figure 1). These results suggest that TAC's have a pharmacologically favorable and selective toxicity against trophozoites over epithelial cells.

Based on these comparative analyses, ALC was the garlic's derivative with the highest antigiardial activity, with the lower HOMO value, with the highest thiol-modifying activity and with the higher cysteine protease inhibitory capacity. Due to these 


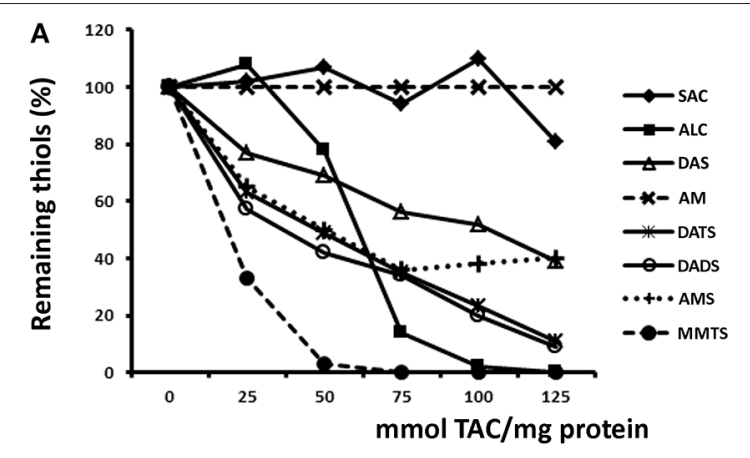

B

\begin{tabular}{cc}
\hline Compound & MBC (mmol/mg protein) \pm SD \\
\hline MMTS & $55.45 \pm 3.2$ \\
SAC & $1260.99 \pm 125.6$ \\
ALC & $93.84 \pm 12.8$ \\
DAS & $351.34 \pm 78.9$ \\
AM & NR \\
DATS & $201.61 \pm 33.4$ \\
DADS & $224.58 \pm 18.8$ \\
AMS & $845.96 \pm 78.1$
\end{tabular}

FIGURE 3 | Inhibition of formation of thiol- dithionitrobenzoic acid (DTNB) complexes in protein extracts of $\mathrm{G}$. duodenalis trophozoites by thioallyl compounds (TACs). (A) Parasite extracts (100 $\mu \mathrm{g})$ were incubated with increasing concentrations of the indicated TACs then the thiol-derivatizing agent DTNB was added to the mixture. Samples without TAC were taken as controls with $100 \%$ thiols. Points represent the mean values of two independent experiments. Lines are as follows: S-allyl Cysteine (filled diamonds), Allicin (filled squares), Diallyl Sulfide (open triangles), Allyl Mercaptan (taches), Diallyl Trisulfide (astereisks), Diallyl Disulfide (open circles), Allyl-Methyl Sulfide (crosses), and Methyl Methanethiosulfonate (closed circles). (B) The values of the maximal blocking concentrations (MBC) for each TAC were calculated using a standard curve using cysteine.

properties, ALC was chosen in further studies to analyse its mechanism of action over trophozoites at different levels.

\section{Allicin Has a Primary Cytolytic Mode of Action Like Age Against Giardia Trophozoites}

Since AGE had previously showed a detrimental effect on trophozoite's integrity followed by a decreased functionality of metabolic enzymes, we tested if ALC could have an effect as observed with whole garlic extracts. In these assays, the TBE protocol was also included in order to assess whether the integrity of trophozoite's membrane is primarily targeted by ALC. As expected, SCLM was the most sensitive method where cell viability completely decreased at concentrations below $0.8 \mathrm{mM}$ ALC while all other methods still displayed viability rates of $>20 \%$ (Figure 6A). Thus parasite replication was initially suppressed at $600 \mu \mathrm{M}$ ALC; the other two physiological methods (DCC and TBE) showed a concomitant decrease of viability (1.08 and $1.12 \mathrm{mM}$, respectively) and the two enzyme-based assays
(FDA-PI and MTT) showed the lowest sensitivity (Figure 6B), suggesting that ALC primarily affected the cellular replication by impairing membrane permeability hence cellular integrity, with a secondary effect on the activity of metabolic enzymes as oxidoreductases and diesterases. When compare the AGE with ALC the latter had a primary cytolytic mechanism on trophozoites albeit oxidoreductases (MTT) were affected more lately by ALC.

\section{Electron Microscopy Analyses of the Damage Caused by Allicin on Giardia Trophozoites}

To further analyse the effect of ALC on trophozoites a standard toxicity (24 h-exposure to $1 \mathrm{MLC})$ and an acute (3 h-exposure to 2 MLC) procedures were used. By SEM, control trophozoites exhibited the typical half a pear-shaped morphology with four pairs of flagella and a relatively smooth surface at ventral (Figure 7A-A) and dorsal (Figure 7A-B) planes. During standard toxicity, ALC provoked the appearance of multiple "holes" particularly in the so-called bare area of the ventral disk, which retained its normal contour (Figure 7A-C, arrow) along to the presence of small protrusions in flagella. The dorsal surface also presented a rough texture that resembled a membrane blebbing process with profuse holes and even nuclear membranes had severe damage (Figure 7A-D, arrows). In other cells the contour of the ventral disk appeared as less rigid and flagella displayed rounded tips (Figures 7A-E,F, asterisks). In parasites under acute ALC toxicity, the bare area showed severe damage in which cell surface presented multiple protrusions (blebbing) and flagella also showed rounded tips (Figure 7A-G, arrow and asterisks) while dorsal surface showed holes with a greater size and damaged areas that allowed the release of cytoplasmic material (Figure 7A-H). Of note, cell shrinkage was not a typical feature because ALC-treated cells did not display a contracted size (compare images Figure 7A and Figure 7B with the corresponding ventral or dorsal views).

At the intracellular level, in control cells the TEM analyses showed integrity of plasma membrane, peripheral vacuoles, nuclei and cytoskeletal elements as ventral disk microtubules and associated microribbons and flagellar axonemes with the typical $9+2$ arrangement (Figures 7B-1,3). Regardless of the standard or acute toxicity protocols, ALC treatment leads to a complete loss of electron density of the intracellular elements and the integrity of plasma membrane, a diffuse destruction of cytoplasmic content rendering a granulose appearance and even nuclear envelopes seemed to be compromised (Figures 7B-2,4). In this context, a profuse condensation of chromatin at the inner periphery was seen (Figure 7B-4). As a consequence, a profuse vacuolisation pattern that occurs frequently with antigiardial drugs was not observed with ALC. Under these conditions, all cytoskeletal elements at ventral disk, cell periphery and flagella remained structurally unaltered and also cell shrinkage was not observed by SEM. These observations reinforced the presence of a cytolytic effect of ALC on Giardia trophozoites that promoted alterations at cellular (and even nuclear) membrane(s)'s integrity associated to further destruction of intracellular structures. To 
A

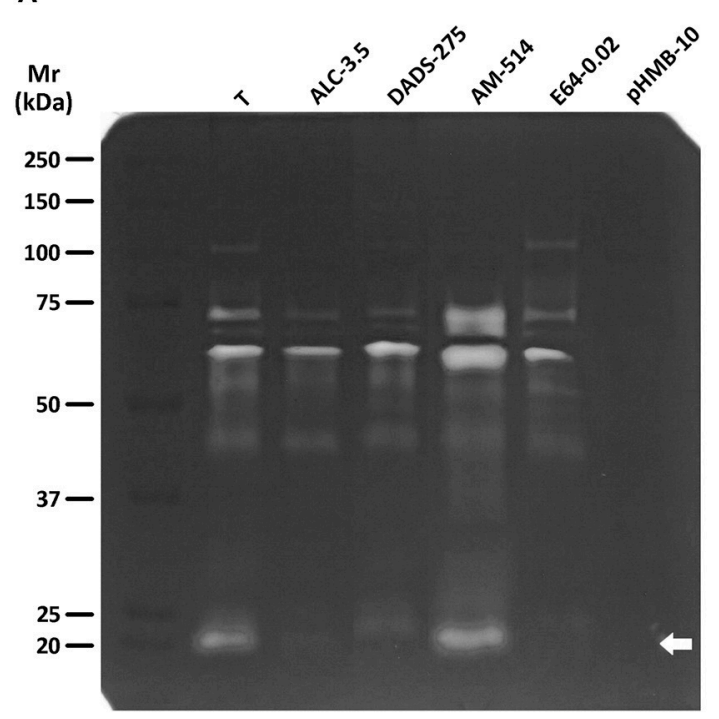

B

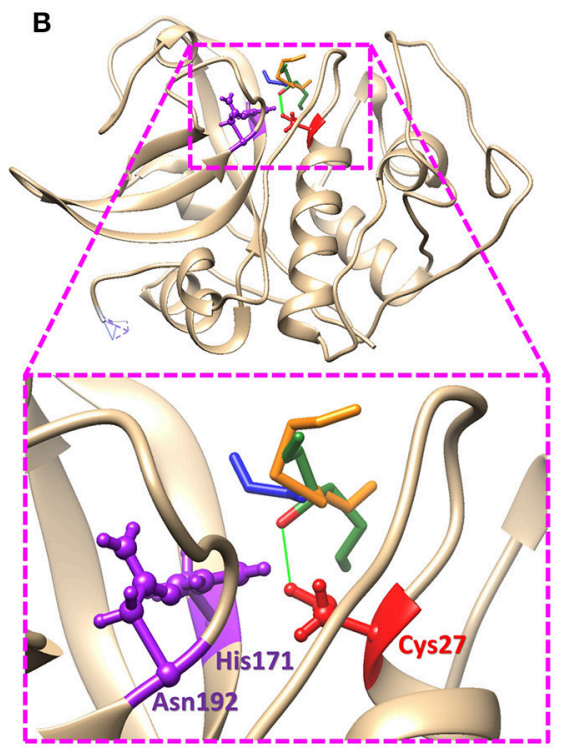

FIGURE 4 | Effect of representative TACs on the proteolytic activity of G. duodenalis trophozoite lysates and docking with giardipain-1. (A) Trophozoite lysates (50 $\mu \mathrm{g}$ ) were electrophoretically separated in $10 \%$ acrylamide- $0.2 \%$ gelatin gels and cysteine protease activities were developed and detected by DTT treatment at pH 5.5 and Coomassie blue staining. Lanes in which extracts were pre-incubated with the three TACs tested (ALC, DADS, and AM) are indicated along with the concentration values $(\mathrm{mM})$ used in each case. The thiol-active inhibitor pHMB $(10 \mathrm{mM})$ and the cathepsin B-specific inhibitor E64 (20 $\mu$ M) were included as controls. Molecular weight standards and its relative mobility (Mr) are as indicated at the left. The arrow points to the band containing the cysteine protease giardipain-1. (B) The most favored docking position of representative TACs (in stick conformation, green: ALC, orange: DADS, blue: AM) at the proximity of the catalytic Cys27 of giardipain-1 in which the Oxygen atom of ALC is predicted to form a bridge with the Hydrogen G1 of Cys27 at a distance of $2.425 \AA$ (green line). The three catalytic residues (Cys26, His171, and Asn192) are represented in ball-and-stick conformation.
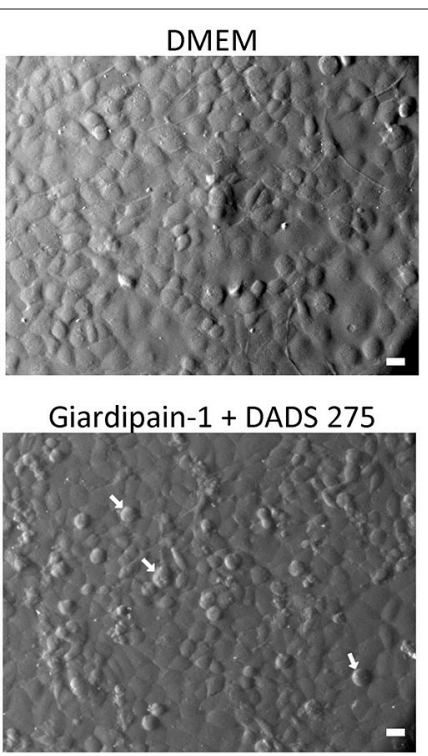

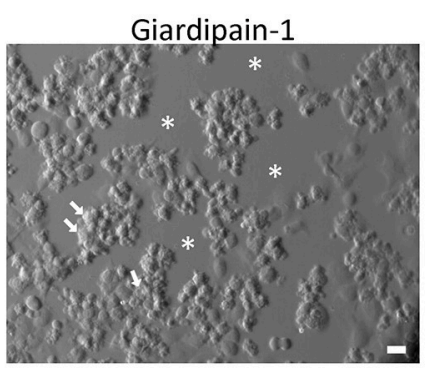

Giardipain-1 + AM 514

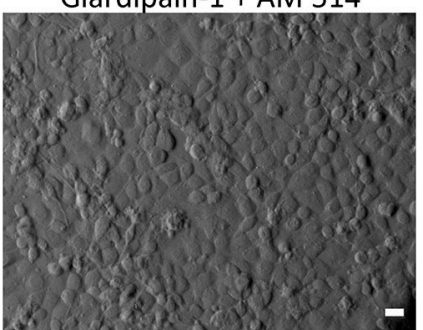

Giardipain-1 + ALC 3.5

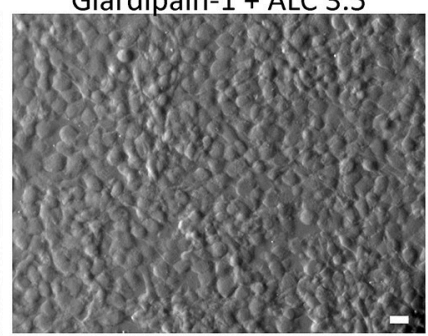

Giardipain-1 + E64 0.02

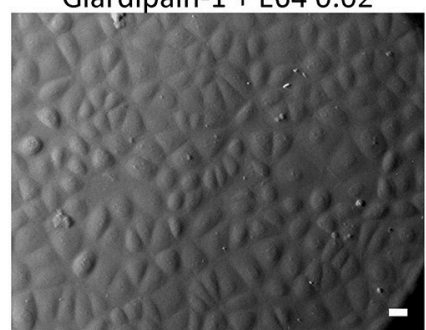

FIGURE 5 | Effect of garlic TACs on the cytolytic damage caused by giardipain-1 in epithelial IEC6 cell monolayers. Confluent IEC6 cells were exposed for 100 min at $37^{\circ} \mathrm{C}$ to affinity chromatography-purified giardipain-1 alone or pre-incubated with the concentrations indicated (in $\mathrm{mM}$ ) of representative TACs that caused inhibition of its protease activity in zymograms and monolayers were observed by Nomarski optics. Asterisks denote zones of monolayer destruction and arrows point to cells undergoing apoptotic death as indicated by membrane blebbing, shrinkage, and shape degeneration. Bars: $20 \mu \mathrm{m}$.

gain more insights on the ALC-mediated damage, we tested whether programmed cell death, oxidative stress and cell cycle arrest could be induced by ALC and then we compared these data with those obtained using ABZ which effects under similar conditions have been already described (Martínez-Espinosa et al., 2015). 


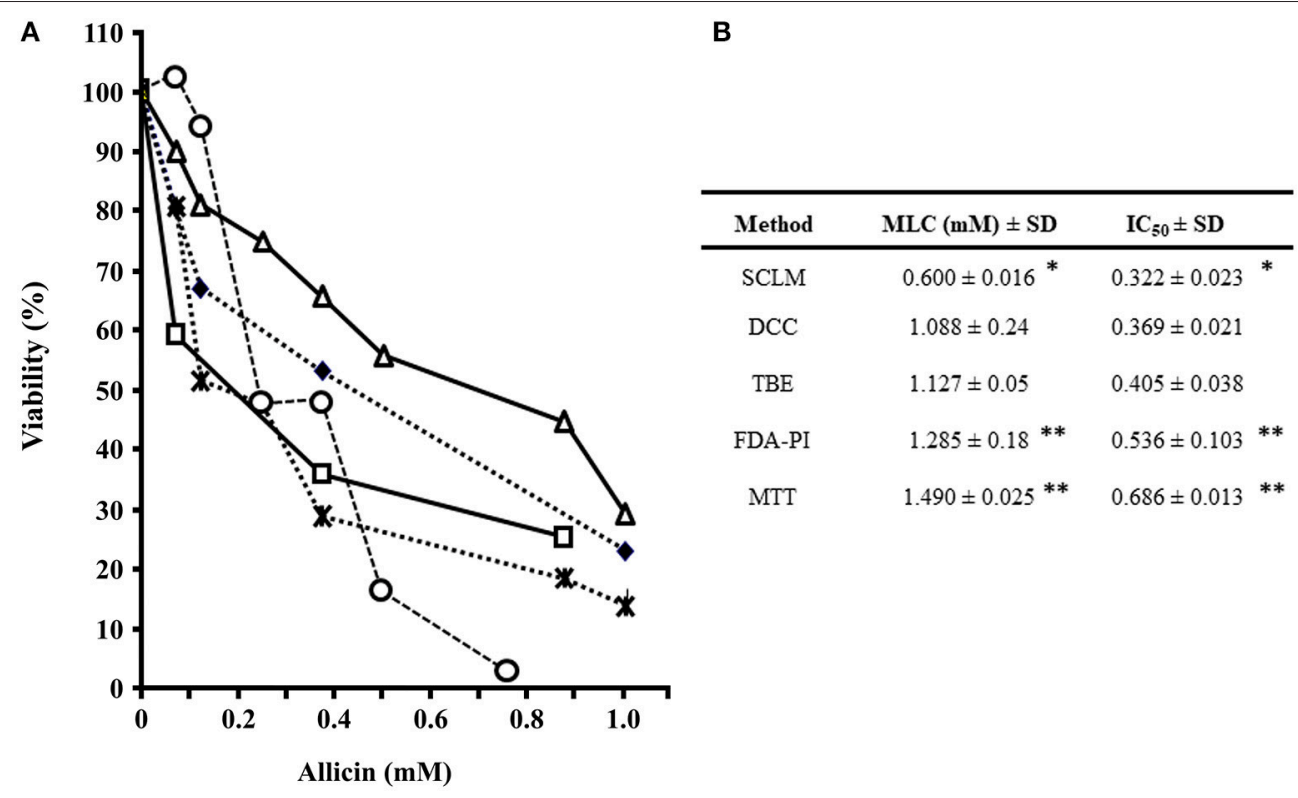

FIGURE 6 | Evaluation of suceptibility of G. duodenalis trophozoites to allicin using five methods. (A) Parasites $\left(1 \times 10^{6}\right)$ were exposed to increasing quantities of $2.5 \% \mathrm{ALC}$ for $24 \mathrm{~h}$ and cellular viability was determined by several methods as previously described (Argüello-García et al., 2004). Values correspond to results from three independent experiments. Lines are as follows: subculture in liquid medium (open circles), fluorescein diacetate-propidium iodide staining (FDA-PI) staining (filled diamonds), direct cell count (taches), 3-(4,5-dimethyl-2-thiazolyl)-2,5-diphenyl-2-H-tetrazolium bromide (MTT) reduction (open triangles) and trypan blue exclusion (open squares). (B) The values of $\mathrm{IC}_{50}$ and MLC were calculated by the least square method. *Significantly lower than any of the other methods at $P<0.05$.

${ }^{*}$ Significantly higher than SCLM, DCC, and TBE $(P<0.05)$.

\section{Pro-apoptotic, Non-prooxidant and G2-Arresting Effect of Allicin on Trophozoites}

Based on the fact that ALC caused cytolysis in G. duodenalis trophozoites, it was of interest to determine the way by which parasites were killed by this TAC. To assess if ALC at increasing concentrations induces apoptotic or necrotic cell death in G. duodenalis trophozoites, anti-annexin V antibodies coupled to FITC and PI were used as markers of apoptosis and necrosis, respectively. In these assays, $\mathrm{ABZ}$ was used as control because of its known ability to induce apoptosis-like death in G. duodenalis (Martínez-Espinosa et al., 2015). As can be seen in a representative experiment shown in Figure 8, upon exposure to ALC at MLC $(0.6 \mathrm{mM}) 10.2 \%$ of trophozoites were at early apoptosis and $18.6 \%$ displayed late apoptosis and by increasing ALC concentration up to twice the MLC (i.e., $1.2 \mathrm{mM}$ ) threetimes more cells were at apoptosis ( $46.6 \%$ in early and $44.0 \%$ in late stage, respectively). In all samples the percentages of cells in necrosis was always $<2.5 \%$. Control trophozoites exposed to ABZ even at 1.5 times its MLC $(0.48 \mu \mathrm{M})$ only induced $41.0 \%$ cells in apoptosis and 5\% cells were necrotic. These results indicated that ALC leads to a marked apoptosis-like cell death in trophozoites.

Next, we tested if apoptosis-like death induced by ALC was associated with oxidative stress. In this, ROS were monitored in ALC-exposed trophozoites using the fluorescent tracer $\mathrm{H}_{2}$ DCFDA. Figure 9 shows representative results in which, as compared to controls, only $0.75 \%$ cells were positive for ROS even using twice the MLC of ALC (1.2 mM) while using the control drug $\mathrm{ABZ}$ up to $33.85 \%$ of trophozoites displayed ROS formation as previously reported (MartínezEspinosa et al., 2015). With the well-known ROS inducer tertbutyl hydroperoxide (TBHP) up to $17.1 \%$ cells were ROSpositive. These results demonstrated that ALC does not induce oxidative stress in G. duodenalis trophozoites as a deathassociated mechanism.

Further flow cytometry analyses to determine the point(s) at which ALC interrupts cell cycle progression of vegetative trophozoites (Figure 10) showed that in control cells most of these were at G2 phase (53.3\%) followed by a subpopulation at $S$ phase $(26.2 \%)$ whereas a lower proportion of cells were at G1 phase (13.4\%) and the boundary G2/M contained $6.9 \%$ of cells. When trophozoite cultures were exposed to MLC and twice the MLC of ALC $(0.6 \mathrm{mM}$ and $1.2 \mathrm{mM})$ there were some changes: a marked decrease in G1 subpopulation with both ALC concentrations (7.4 and 2.2\%, respectively), a significant decrease in S subpopulation with $1.2 \mathrm{mM}$ ALC (5.7\%) and an important increase in cells at G2 phase (61.0 and $75.3 \%$, respectively). Interestingly, cells at $\mathrm{G} 2 / \mathrm{M}$ phase did not significantly change (4.4 and 5.7\%). As a reference, $1.35 \mu \mathrm{M}$ ABZ partially decreased cells $S$ at phase $(22.1 \%)$ and partially arrested cells at G2 phase (69.9\%) as previously reported (Martínez-Espinosa et al., 2015). All these data suggest that cytotoxic ALC concentrations allow an exit of G1 and 
A

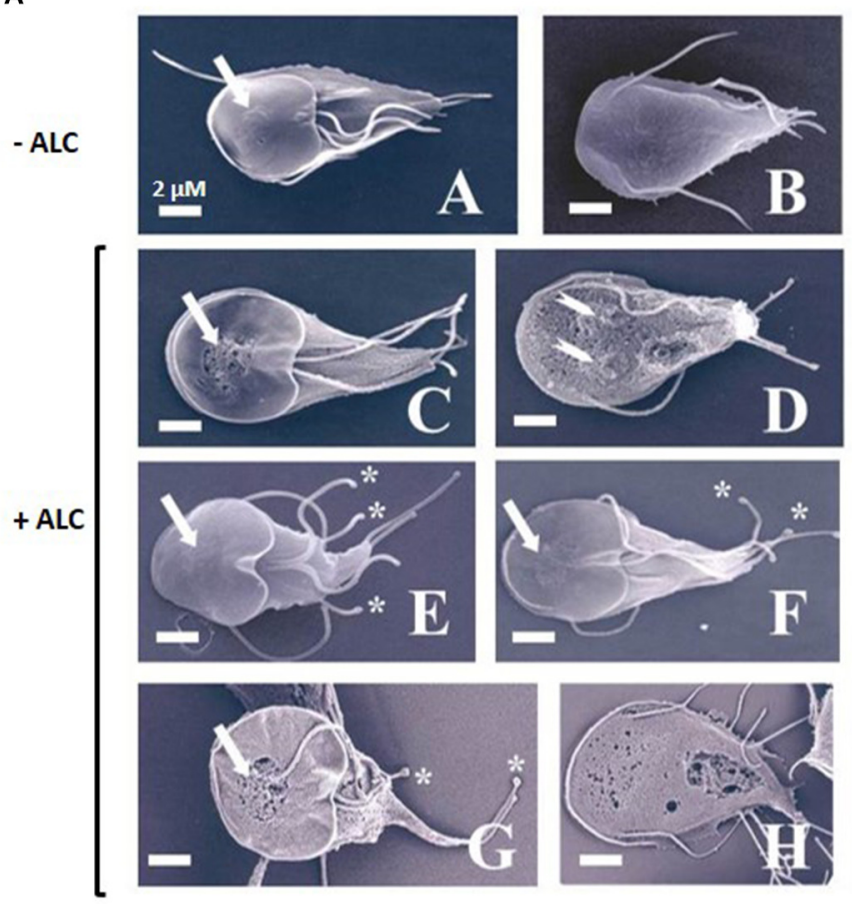

B

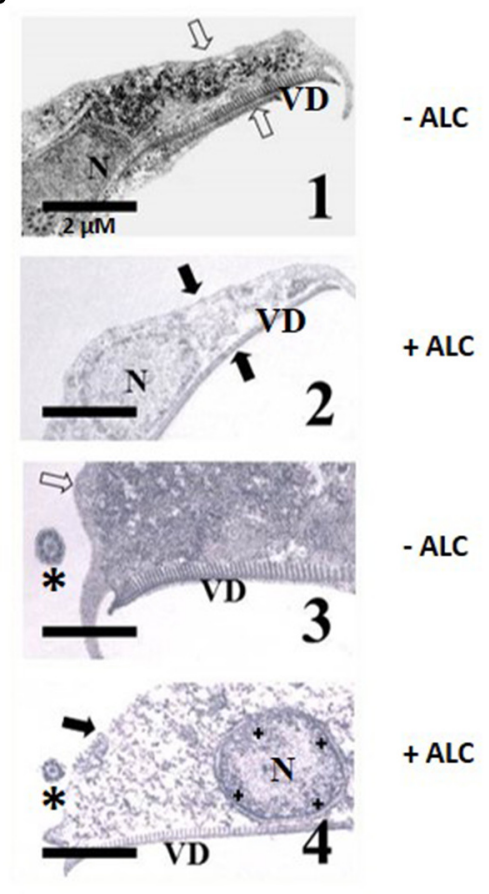

FIGURE 7 | Analysis by scanning (A) and transmission (B) electron microscopy of G. duodenalis trophozoites exposed to allicin. (A) Parasites $\left(1 \times 10^{6}\right)$ were either not exposed (A,B) or exposed to $600 \mu \mathrm{M}$ ALC (C-F) for $24 \mathrm{~h}$ or $1.2 \mathrm{mM} \mathrm{ALC}$ for $3 \mathrm{~h}(\mathrm{G}, \mathrm{H})$ at $37^{\circ} \mathrm{C}$. Trophozoites are shown in ventral $(\mathrm{A}, \mathrm{C}, \mathrm{E}-\mathrm{G})$ and dorsal $(\mathrm{B}, \mathrm{D}, \mathrm{H})$ views. The higher roughness of cell surface in images $\mathrm{C}-\mathrm{H}$ as compared to $\mathrm{A}, \mathrm{B}$, except over the ventral disk, are indicative of a degree of membrane blebbing. Arrows denote the so-called "bared area" of the ventral disk and asterisks point to tip rounding at flagella. (B) Parasites not exposed $(1,3)$ and exposed to $600 \mu \mathrm{M}$ ALC $(2,4)$ for $24 \mathrm{~h}$ at $37^{\circ} \mathrm{C}$. Trophozoites are shown in longitudinal $(1,2)$ and cross-sections $(3,4)$. Arrows indicate the plasma membranes, asterisks show flagellar axonemes and crosses show inner peripheral areas of nucleus with chromatin condensation. N, nuclei; VD, ventral disk. Bars correspond to the indicated size.

$\mathrm{S}$ phases but most parasites were partially arrested at the G2 phase.

\section{Antiparasitic Efficacy of AGE and ALC in Experimental Giardiasis}

The pre-clinic and potential therapeutic effectiveness of AGE and ALC to treat giardiasis was evaluated in this work using the well-established model of experimental infections in Mongolian gerbils (Belosevic et al., 1982; Argüello-García and OrtegaPierres, 1997). As shown in Figure 11, AGE-treated animals exhibited a significant reduction in trophozoite numbers with all doses tested as compared to PBS-treated, control gerbils. However only partial cure rates were obtained with 385 (2 out of 6 gerbils), 770 (3 out of 6), 1,155 (5 out of 6 ) and $770 \mathrm{mg} / \mathrm{kg}$ twice (5 out of 6 ) while none gerbil was cured with $1,515 \mathrm{mg} / \mathrm{kg}$. Interestingly in ALC-treated animals, a progressive decrease in parasite numbers was observed upon increasing doses and cure rates increased as follows: 3 out of 6 gerbils with $35 \mathrm{mg} / \mathrm{kg}, 5$ out of 6 with $70 \mathrm{mg} / \mathrm{kg}, 6$ out of 6 with $138 \mathrm{mg} / \mathrm{kg}$ and 5 out of 6 with $276 \mathrm{mg} / \mathrm{kg}$. These two latter doses were even more effective than the control drug MTZ that cured 3 out of 6 gerbils with $36 \mathrm{mg} / \mathrm{kg}$ and 5 out of 6 animals at twice dose.

All these data showed that ALC at increasing single doses had a dose-dependent and consistent giardicidal effect that caused a complete elimination of trophozoites in infected animals and a partially effective action using AGE. In spite that ALC is a major thiosulfinate in garlic extracts (Lawson, 1996) these differences are likely attributed to a distinct availability of ALC at intestinal lumen of infected animals to reach its targets in resident trophozoites.

\section{DISCUSSION}

Garlic has widely proven to be a rich source of nutraceutical compounds (Bhagyalakshmi et al., 2007) that are mostly organosulfur compounds as TACs. Indeed, garlic's TACs have a double benefit, i.e., health promoting and illness fighting, upon dietary or supplementary consumption. In recent years TACs contained in aqueous (e.g., ALC), ethanol (e.g., SAC) or oily (e.g., allyl sulfides as DATS, DADS, DAS, AMS, AM) garlic extracts have been studied in relation to the treatment of infectious diseases because of their direct effects over a plethora of pathogens (Ankri and Mirelman, 1999; D’Souza et al., 2017). In this work, the seven TACs mentioned above were evaluated in G. duodenalis trophozoites regarding its cytotoxic mechanism and therapeutic potential in experimental giardiasis.

Our results showed that the AGE's MLC as determined in this work $(425 \pm 47 \mu \mathrm{g} / \mathrm{mL})$ is slightly higher than the value 

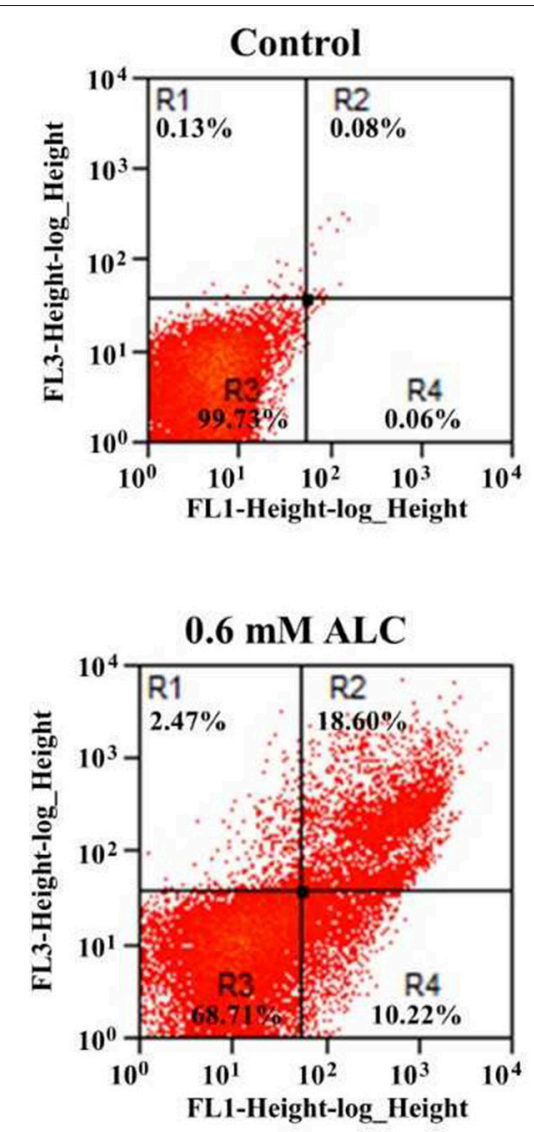
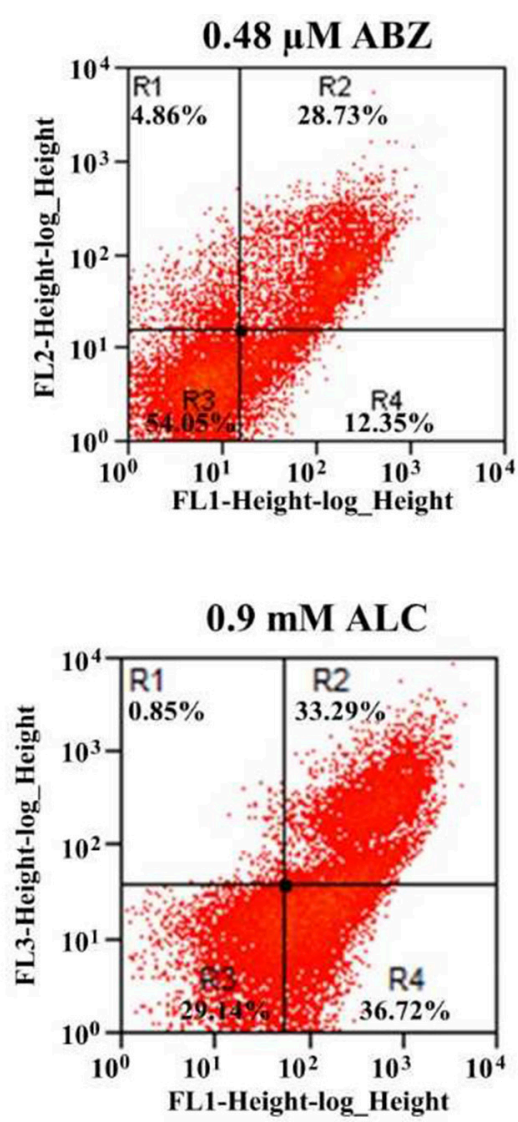
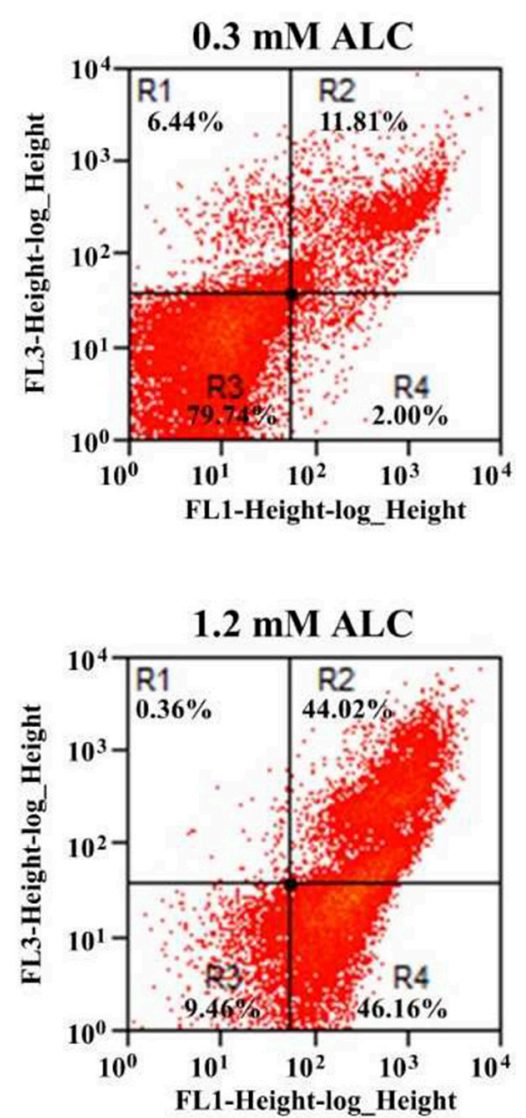

FIGURE 8 | Allicin promotes apoptosis-like death in G. duodenalis trophozoites. Parasites $\left(1 \times 10^{6}\right)$ were exposed to $1.0 \%$ double distilled water pH 6.5 (Control) or the indicated concentrations of ALC for $24 \mathrm{~h}$ at $37^{\circ} \mathrm{C}$ then stained with annexin V-PI and processed by flow cytometry. Data shown in the figure are as follows: quadrant R1 are cells positive for necrosis $(\mathrm{PI}+$ ); quadrant R2 are cells positive for late apoptosis (annexin $\mathrm{V}+/ \mathrm{PI}+$ ); quadrant R3 are cells negative for both markers and quadrant R4 are cells positive for early apoptosis (annexin $\mathrm{V}+$ ). As a positive control, trophozoites were exposed to the indicated cytotoxic concentration of albendazole (ABZ). Percentages of total cells are indicated within each quadrant. The dot plots are representative of two independent experiments.

of $300 \mu \mathrm{g} / \mathrm{mL}$ previously determined (Harris et al., 2000). It is tempting to speculate that the use of two parasite strains (WB vs. Portland-1) along to different garlic sources (fresh cloves macerated in water vs. freeze-dried powder vortexed in culture medium) may account for the differences obtained in both studies. In addition, values of MLCs of four similar TACs used in our study and in another work (AM, AMS, DAS, and DADS) differed quantitatively, albeit AM and DADS were in both cases more active against trophozoites than either DAS or AMS. When its effect was compared to the one observed against other pathogens, AGE had a lower effectivity against enteral bacteria e.g., Helicobacter pylori (MLC: from 5 to $25-400 \mathrm{mg} / \mathrm{mL}$ ) (Cellini et al., 1996; Moghadam et al., 2014) or even anaerobic protozoa as Trichomonas gallinae (MLC: $75 \mathrm{mg} / \mathrm{mL}$ ) (Seddiek et al., 2014) thus highlighting the importance of the conspicuous repertoire of thiol-containing proteins and the dependence on cysteine import and metabolism in G. duodenalis (Ali and Nozaki, 2007) concomitant to its higher susceptibility to garlic constituents.

The use of physiological and enzyme activity based protocols were useful to determine that AGE had a cytolytic mechanism (i.e., TBE and DCC assays displayed high sensitivity) concomitant to an impaired oxidoreductase capacity as assessed by MTT assays and a further impairment of diesterase activity in trophozoites as shown by the lower sensitivity of FDA-PI assays. The effect of garlic components on the integrity of cell membranes were in agreement with a previous report (Harris et al., 2000) that showed a collapse in the electrochemical potential of trophozoite plasma membranes exposed to AGE and allyl alcohol. In this context, the abundance of cysteine (i.e., thiol)-rich proteins in Giardia surface proteins (Adam, 2001; Pinto et al., 2006; Ali and Nozaki, 2007) play a direct role as primary targets of garlic constituents, especially organosulfur compounds as TACs. Likewise, it is possible that some enzymes having a rate-limiting role in glucose metabolism of $G$. duodenalis and harboring cysteine residues critical for activity modulation (e.g., triosephosphate isomerase) (Reyes-Vivas et al., 2007) are also affected by garlic components. Further assays using recombinant or purified target molecules may be useful to provide more data on the effects of garlic components on Giardia trophozoites. 

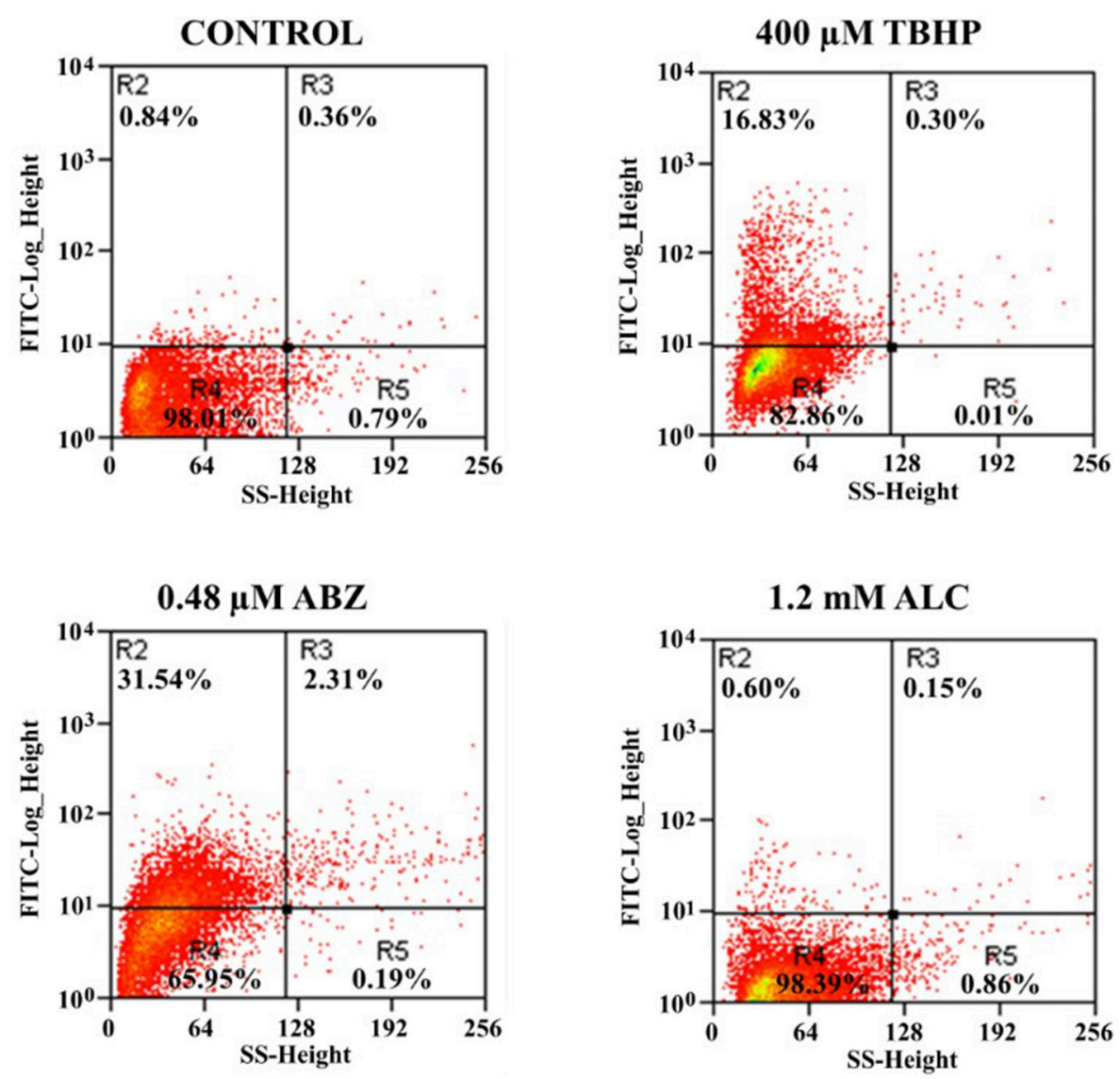

FIGURE 9 | Allicin does not cause reactive oxygen species (ROS) formation in G. duodenalis trophozoites. Parasites $\left(1 \times 10^{6}\right)$ were exposed to $1.0 \%$ double distilled water pH 6.5 (Control) or the indicated concentrations of ALC, tert-butyl hydroperoxide (TBHP, positive control) or prooxidant $\mathrm{ABZ}$ for $24 \mathrm{~h}$ at $37^{\circ} \mathrm{C}$ then incubated with the ROS-monitoring agent $\mathrm{H}_{2} \mathrm{DCFDH}$ and processed by flow cytometry. Data shown in the figure are as follows: quadrants R2-R3 are cells positive for ROS and quadrants R4-R5 are cells negative for ROS. Percentages of total cells are indicated within each quadrant. The dot plots are representative of two independent experiments.

The relation between TAC structure and giardicidal activity showed that the increasing numbers of sulfur atoms are important for this effect and remarkably, points out that the presence of the sulfur-attached oxygen atom in ALC accounts for its maximal efficacy. When comparing the relative giardicidal activity of these seven TACs (ALC> DATS $>$ DADS $>$ AM $>$ DAS $>$ SAC $>$ AMS) with its HOCl-scavenging capacity (SAC> DATS $>$ DAS $>$ ALC $>$ DAS $>$ AM $>$ AMS; Argüello-García et al., 2010) it was observed that garlic's TACs have a wide biological mechanisms suggesting that there is a need to choose the best compound for a defined benefit, either therapeutic (e.g., anticancer and antimicrobial) or antioxidant that will finally induce health-promoting activities upon consumption (Capasso, 2013). As examples, AMS could provide low beneficial effects whereas DATS (sell as Dasuansu in China) could give multiple benefits while ALC could also provide several benefits but with a higher efficacy as antimicrobial agent. Nevertheless, it is still necessary to compare these TACs in other systems to obtain compelling data on the effects of TACs. In addition, the molecular descriptor $E_{\text {НОМО }}$ was useful to predict the antigiardial effect of
TACs and interestingly it was a partial contributor for HOClscavenging activities of these TACs (Argüello-García et al., 2010). Considering that HOMO are electron orbitals that could act as electron donors and LUMO are electron acceptor orbitals in a given molecule, these data suggest that ALC exhibiting the

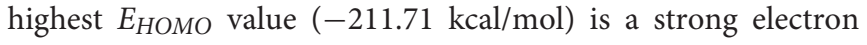
donor that could hence act as a nucleophile toward parasite's molecules bearing electron-acceptor groups e.g., thiols (R-SH) at a greater extent as compared with all other TACs used leading to trophozoite death.

There is a growing body of information regarding the efficacy of ALC against other protozoan pathogens. For example, in the human intestinal parasite Entamoeba histolytica the reported $\mathrm{IC}_{60}\left(500 \mu \mathrm{M}\right.$; Ankri et al., 1997) is similar to the $\mathrm{IC}_{50}$ value obtained for G. duodenalis in this work using the same assay $(686 \mu \mathrm{M})$ again reflecting the cysteine-rich content and thioldependent metabolism of these mitosome-containing parasites (Ali and Nozaki, 2007). In the also diplomonad but aerotolerant, hydrogenosome-containing fish parasite Spironucleus vortens ALC has a higher $\mathrm{IC}_{50}$ value ( $>1.12 \mathrm{mM}$; Millet et al., 2011) that 

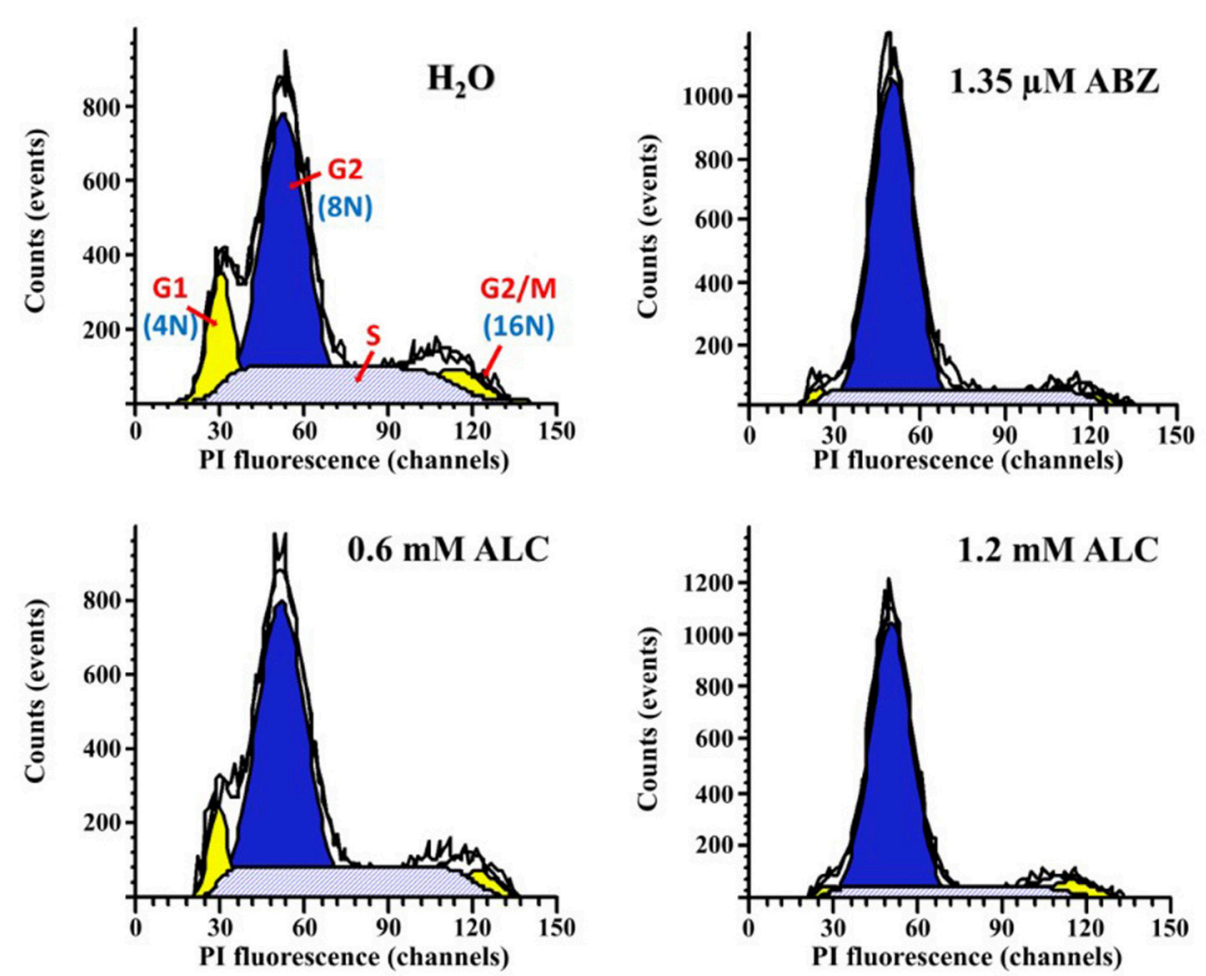

\begin{tabular}{ccccc}
\hline Sample & G1 & S & G2 & G2/M \\
\hline Control $\left(\mathrm{H}_{2} \mathrm{O}\right)$ & 13.44 & 26.25 & 53.34 & 6.97 \\
$0.6 \mathrm{mM} \mathrm{ALC}$ & 7.43 & 27.03 & 61.09 & 4.44 \\
$1.2 \mathrm{mM} \mathrm{ALC}$ & 2.22 & 5.72 & 75.53 & 5.72
\end{tabular}

FIGURE 10 | Allicin partially arrests G. duodenalis trophozoites at G2 phase. Parasites $\left(1 \times 10^{6}\right)$ were exposed to $1.0 \%$ double distilled water pH 6.5 (Control) or the indicated concentrations of ABZ (positive control for cell cycle arrest) or ALC for $24 \mathrm{~h}$ at $37^{\circ} \mathrm{C}$. Nuclei of permeabilised and RNAse A-treated cells were stained with PI and processed by flow cytometry. The areas under curve (AUC) corresponding to G1, S, G2, or G2/M cell cycle phases are indicated in the control histogram. Percentages of cells within each AUC are shown in the table at the bottom of histograms. Data are representative of two independent experiments.

is likely linked to a lower susceptibility of its glutathione-based metabolism (Williams et al., 2014) to this TAC. In contrast, the small intestinal chicken parasite Eimeria tenella displays a poor susceptibility to ALC ( IC $_{99}=11.1 \mathrm{mM}$; Alnassan et al., 2015) due at least in part to its diverse metabolism highlighted by several shunt-off pathways like the mannitol cycle (Schmatz, 1997).

As far as the mechanism of cytotoxic action of ALC is concerned, its cytolytic, membrane-damaging effects were evidenced by the higher sensitivity of physiological methods (DCC and TBE) and electron microscopy analyses. In contrast with AGE, the MTT reduction assay displayed the lowest sensitivity of all methods used, suggesting that cellular oxidoreductases are not primary targets of ALC. Although ALC behaved as AGE did against trophozoite's integrity, it had a thioldisulfide exchange capacity that correlated to and accounted for its highest giardicidal efficacy as compared to all other TACs tested. Therefore, the derivatizing reaction mediated by TACs on giardial proteins exposing thiol-groups to form S-allylmerecpto adducts $\left(\mathrm{R}-\mathrm{SH} \rightarrow \mathrm{R}-\mathrm{S}-\mathrm{S}-\mathrm{CH}_{2}-\mathrm{CH}=\mathrm{CH}_{2}\right.$ ) was proven to be a major mechanism promoting trophozoite's death. However, this general reaction of ALC (Rabinkov et al., 1998) could take place at certain proteins that have important implications for cell viability, proliferation, and differentiation in G. duodenalis. Among these are cysteine proteases that intrinsically have the catalytic triad Cys-His-Asn. These constitute a repertoire of around 10 proteins in this parasite, participate in host cell damage and are feasible candidates for new therapeutic strategies in giardiasis (DuBois et al., 2006; Ali and Nozaki, 2007; Ankarklev et al., 2010; Gargantini et al., 2016; Cabrera-Licona et al., 2017; Ortega-Pierres et al., 2018). The zymogram anlaysis presented in Figure 4 indicates that garlic TACs are effectively inhibitors of several cysteine proteases in trophozoite lysates 


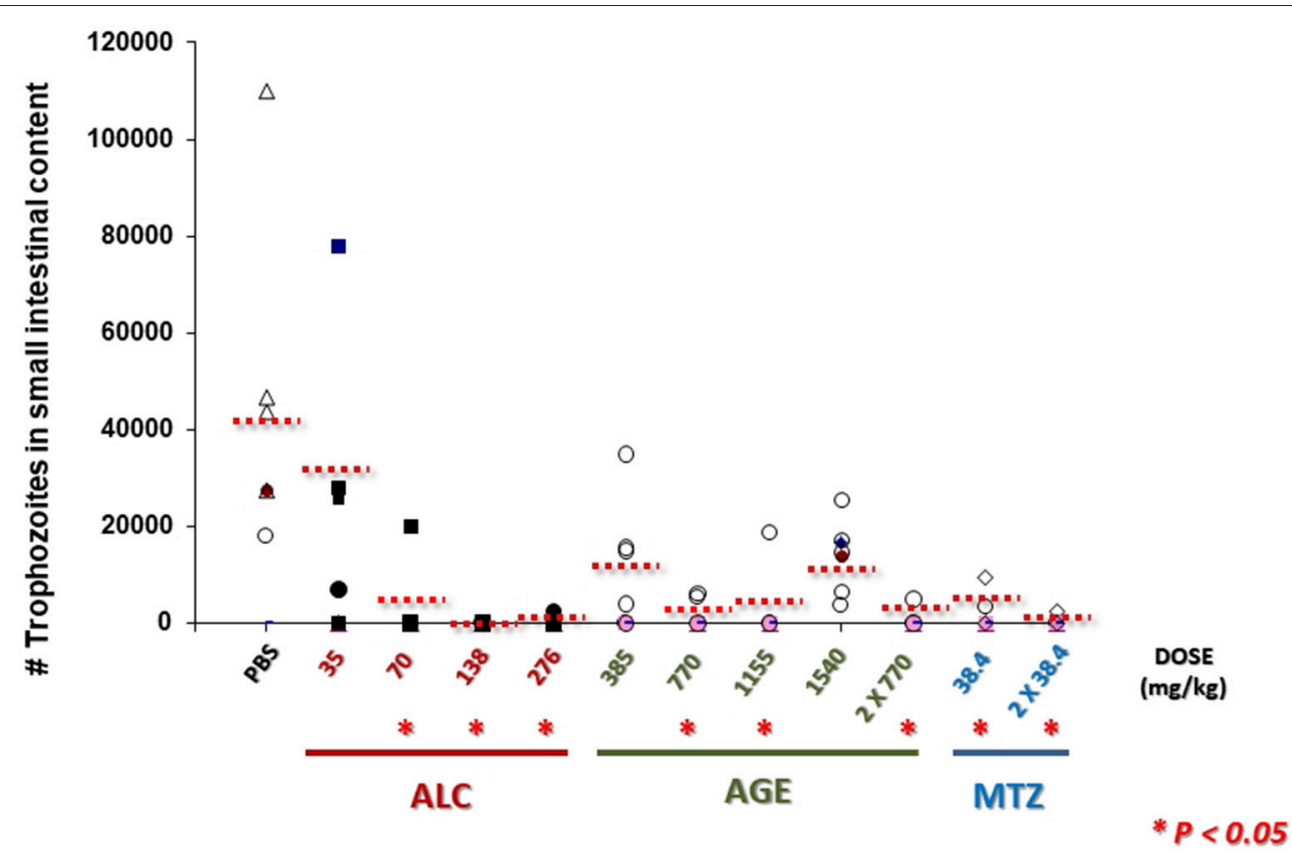

FIGURE 11 | AGE and allicin diminish and eliminate G. duodenalis trophozoites in small intestines of infected gerbils. Male M. unguiculatus were intragastrically inoculated with $1 \times 10^{6}$ trophozoites per os. At day 10 p.i. gerbils were treated with AGE (single or doubled doses), ALC at single doses or metronidazole (MTZ) at single or double dose as indicated. At day 13 p.i. trophozoites in intestinal contents (10 cm-long sections) were counted. Punctuated lines indicate the mean values of intestinal trophozoites for each group. Asterisks indicate counts significantly lower than control group (PBS) at $P<0.05$.

with ALC displaying a remarkably higher inhibitory action than DADS in good agreement with their thiol-modifying activities determined herein and in recent reports in other parasite models (Waag et al., 2010). Of particular interest was the marked inhibition of the proteolytic activity of giardipain-1, a secreted virulence factor of $G$. duodenalis trophozoites, observed with ALC, DADS, and E64 in zymograms, Giardipain-1 has recently been reported to exert pro-apoptotic effects in epithelial cells monolayers including membrane blebbing, external phosphatidylserine exposure, loss of barrier function, caspase 3 activation, and altered localization of tight junction proteins as occludin and claudin-1 (Ortega-Pierres et al., 2018). Moreover, representative TACs as are ALC, DADS and AM were not only able to reduce the cytopathic effects of giardipain-1 but to display a much more marked effect in trophozoites' viability over epithelial cell integrity. These facts suggest that ALC is a promising candidate in further studies at preclinical level in giardiasis.

Other likely targets of ALC and remainder TACs in Giardia are the variable surface proteins (VSPs) that are a family with over 230 members having $10-12 \%$ of cysteine residues in their sequence that are involved in antigenic variation and other functions, the high-cysteine membrane proteins (HCMp) family with role in epithelium-trophozoite interactions and cell differentiation along with the iron-sulfur cluster containing protein family (e.g., ferredoxins) involved in redox metabolism. Studies in our group on these interactions are now under progress.

At the level of cellular processes, ALC induced apoptotic-like cell death and arrest at G2 phase with thiol but not oxidative stress as shown by flow cytometry studies. When the effects of ABZ, a potent antigiardial agent currently prescribed, it was observed that ALC also promoted apoptosis-like death as many other antigiardial agents from synthetic or plant resources; nevertheless ALC did not cause ROS formation suggesting that TACs are not significantly metabolized by trophozoites unlike most of prescribed drugs as ABZ, MTZ, furazolidone or nitazoxanide (Gardner and Hill, 2001). On the other hand, the putative induction of thiol stress in G. duodenalis trophozoites caused by ALC and other TACs by modification of thiol groups to S-allylmercapto adducts (Figure 3) is similar to that reported in Escherichia coli; however, in these bacteria ALC induced oxidative stress as assessed by the upregulation of antioxidant enzymes such as OxyR, alkyl hydroperoxide reductase and thioredoxins 1 and 2 (Müller et al., 2016). Interestingly ALC also induced oxidative stress with the same probe used here $\left(\mathrm{H}_{2} \mathrm{DCFDA}\right)$ in the mitochondria-containing protozoan parasite Leishmania infantum albeit the absence of phosphatidylserine externalization at cell membrane as assessed by annexin $\mathrm{V}$ and positive staining with PI indicated a necrotic process of cell death (Corral et al., 2016). All these studies shed light on the multiplicity of microbicidal effects of ALC regardless of its well-recognized mode of action on cellular thiols.

In the experimental gerbil model of giardiasis ALC demonstrated a potential utility at single doses of 70 (5/6 gerbils cured) and $138 \mathrm{mg} / \mathrm{kg}$ (6/6 gerbils cured) while AGE was effective using two doses of $770 \mathrm{mg} / \mathrm{kg}$ (5/6 gerbils cured). In our experience ALC by intragastric route shows a lethal dose in gerbils of $>400 \mathrm{mg} / \mathrm{kg}$ and in other rodents this TAC displays oral lethality at $300 \mathrm{mg} / \mathrm{kg}$ (mouse) and $980 \mathrm{mg} / \mathrm{kg}$ (rat). In 
spite of this apparently narrow margin of therapeutic security for ALC, in further studies splitting into two or more days the treatment could reduce these doses. Some encouraging examples on this regard have been reported with experimental infections of mice by systemic protozoa as Babesia microti where $30 \mathrm{mg} / \mathrm{kg}$ ALC orally for 5 days significantly reduced parasitemia and with Plasmodium berghei in which 4 daily doses of ALC at either 9 $\mathrm{mg} / \mathrm{kg}$ (orally) or $8 \mathrm{mg} / \mathrm{kg}$ (intravenously) markedly reduced mortality (Coppi et al., 2006; Salama et al., 2014). Concurrent to these purposes is the possibility to improve the bioavailability of ALC or AGE components at intestinal milieu using carriers such as nanoparticles (Pinilla et al., 2017; Soumya et al., 2017).

In summary, the results obtained in this study highlight the cytolytic mechanism involved in the cytotoxic activity of AGE and particularly TACs as ALC that also produce thiol stress, apoptosis-like cell death as a consequence of targeting multiple proteins in G. duodenalis including cysteine proteinase activities as shown in this work. The identification and characterization of interactions of garlic components/derivatives with giardial biomolecules deserves future studies and indicates that ALC is a promising antigiardial agent with concomitant benefits for host health.

\section{ETHICS STATEMENT}

This study was carried out in accordance with the recommendations of Comité Interno para el Cuidado $y$ Uso de los Animales de Laboratorio (CICUAL) Del Cinvestav, México. According with the Official Mexican Rule (Norma Oficial Mexicana) NOM-062-ZOO-1999. The protocol was approved by the Comité Interno para el Cuidado y Uso de los Animales de Laboratorio (CICUAL) Del Cinvestav, México.

\section{AUTHOR CONTRIBUTIONS}

RA-G and MO-P conceived the work, designed the experiments, and analyzed the data. RA-G and NP-H participated in allicin synthesis. NP-H obtained the values of molecular descriptors.

\section{REFERENCES}

Adam, R. D. (2001). Biology of Giardia lamblia. Clin. Microbiol. Rev. 14, 447-475. doi: 10.1128/CMR.14.3.447-475.2001

Ali, V., and Nozaki, T. (2007). Current therapeutics, their problems, and sulfurcontaining-amino-acid-metabolism as a novel target against infections by “amitochondriate" protozoan parasites. Clin. Microbiol. Rev. 20, 164-187. doi: 10.1128/CMR.00019-06

Alnassan, A. A., Thabet, A., Daugschies, A., and Bangoura, B. (2015). In vitro efficacy of allicin on chicken Eimeria tenella sporozoites. Parasitol. Res. 114, 3913-3915. doi: 10.1007/s00436-015-4637-2

Ankarklev, J., Jerlström-Hultqvist, J., Ringqvist, E., Troell, K., and Svärd, S. G. (2010). Behind the smile: cell biology and disease mechanisms of Giardia species. Nat. Rev Microbiol. 8, 413-422. doi: 10.1038/nrmicro2317

Ankri, S., and Mirelman, D. (1999). Antimicrobial properties of allicin from garlic. Microbes Infect. 1, 125-129. doi: 10.1016/S1286-4579(99)80003-3

Ankri,S., Miron, T., Rabinkov, A., and Wilchek, M., Mirelman, D. (1997). Allicin from garlic strongly inhibits cysteine proteinases and cytopathic effects of Entamoeba histolytica. Antimicrob Agents Chemother. 41, 2286-2288.
MdlV-A performed all techniques of susceptibility assays. IL-R, AM-C, EM-T, and EE-C evaluated extracts and compounds in the gerbil model of giardiasis. RF-L performed the proteolytic activity (zymograms) assyas, the co-culture assays to analyzed representative TACs as possible inhibitors of the cytolytic effect of giardipain-1 on IEC6 cell monolayers and to determine the effect of representative TACs on epithelial IEC6 cell monolayers. RA-G did the docking of with giardipain-1. AG-R performed the electron microscopy (scanning and transmission) studies. RA-G carried out flow cytometry studies. RA-G and MO-P wrote and corrected the manuscript.

\section{ACKNOWLEDGMENTS}

We are grateful to Dr. José Pedraza Chaverri for critically reading the manuscript. We would like to thank Blanca Herrera Ramírez for technical assistance, Víctor Hugo Rosales García for his expert help in flow cytometry studies and Arturo Pérez-Taylor Reyes for artwork. This work was supported in part by Fondo Secretaria de Educación Pública-Consejo Nacional de Ciencia y Tecnología (SEP-CONACYT) México. Grant number 128426.

\section{SUPPLEMENTARY MATERIAL}

The Supplementary Material for this article can be found online at: https://www.frontiersin.org/articles/10.3389/fcimb. 2018.00353/full\#supplementary-material

Supplementary Figure 1 | Determination of the effect of representative TACs on epithelial IEC6 cell monolayers. Confluent IEC6 cells were exposed for $100 \mathrm{~min}$ at $37^{\circ} \mathrm{C}$ to affinity chromatography-purified giardipain- 1 alone (control for cell cytotoxic effect) or to concentrations (in mM) of representative TACs causing inhibition of its protease activity in zymograms (center panels) or corresponding to the MLCs in trophozoites (right panels) of representative garlic TACs (ALC, Allicin; DADS, Diallyl disulfide; AM, Allyl mercaptan). Monolayers were analyzed by Nomarski optics. Asterisks denote zones of monolayer destruction and arrows point to cells undergoing apoptotic death as indicated by membrane blebbing, shrinkage and shape degeneration. Bars: $20 \mu \mathrm{m}$.

Supplementary Table 1 | Values of electronic and molecular transport descriptors calculated for garlic's TACs used in this study.
Anthony, J. P., Fyfe, L., and Smith, H. (2005). Plant active components a resource for antiparasitic agents? Trends Parasitol. 21, 462-468. doi: 10.1016/j.pt.2005.08.004

Argüello-García, R., Cruz-Soto, M., Romero-Montoya, L., and OrtegaPierres, G. (2004). Variability and variation in drug susceptibility among Giardia duodenalis isolates and clones exposed to 5-nitroimidazoles and benzimidazoles In vitro. J. Antimicrob. Chemother. 54, 711-721. doi: $10.1093 / \mathrm{jac} / \mathrm{dkh} 388$

Argüello-García, R., Cruz-Soto, M., Romero-Montoya, L., and Ortega-Pierres, G. (2009). In vitro resistance to 5-nitroimidazoles and benzimidazoles in Giardia duodenalis: variability and variation in gene expression. Infect. Genet. Evol. 9, 1057-1064. doi: 10.1016/j.meegid.2009.05.015

Argüello-García, R., Medina-Campos, O. N., Pérez-Hernández, N., PedrazaChaverrí, J., and Ortega-Pierres, G. (2010). Hypochlorous acid scavenging activities of thioallyl compounds from garlic. J. Agric. Food Chem. 58, 11226-11233. doi: 10.1021/jf102423w

Argüello-García, R., and Ortega-Pierres, M. G. (1997). Giardia duodenalis: analysis of humoral immune response in experimentally infected gerbils (Meriones unguiculatus). Arch. Med. Res. 28, 171-178. 
Belosevic, M., Faubert, G. M., MacLean, J. D., Law, C., and Croll, N. A. (1982). Giardia lamblia infections in Mongolian gerbils: an animal model. J. Infect. Dis. 147, 222-226. doi: 10.1093/infdis/147.2.222

Bhagyalakshmi, N., Thimmaraju, R., Venkatachalam, L., Chidambara-Murthy, K. N., and Sreedhar, R. V. (2007). Nutraceutical applications of garlic and the intervention of biotechnology. Crit. Rev. Food Sci. Nutr. 45, 607-621. doi: 10.1080/10408390500455508

Breeuwer, P., Drocourt, J. L., Bunschoten, N., Zwietering, M. H., Rombouts, F. M., and Abee, T. (1995). Characterization of uptake and hydrolysis of fluorescein diacetate and carboxyfluorescein diacetate by intracellular esterases in Saccharomyces cerevisiae, which result in accumulation of fluorescent product. Appl. Environ. Microbiol. 61, 1614-1619.

Cabrera-Licona, A., Solano-González, E., Fonseca-Liñán, R., Bazán-Tejeda, M. L., Argüello-García, R., Bermúdez-Cruz, R. M., et al. (2017). Expression and secretion of the Giardia duodenalis variant surface protein 9B10A by transfected trophozoites causes damage to epithelial cell monolayers mediated by protease activity. Exp. Parasitol. 179, 49-64. doi: 10.1016/j.exppara.2017.06.006

Capasso, A. (2013). Antioxidant action and therapeutic efficacy of Allium sativum L. Molecules 18, 690-700. doi: 10.3390/molecules 180 10690

Cellini, L., Di Campli, E., Masulli, M., Di Bartolomeo, S., and Allocati, N. (1996). Inhibition of Helicobacter pylori by garlic extract (Allium sativum). FEMS Immunol. Med. Microbiol. 13, 273-277. doi: 10.1111/j.1574-695X.1996.tb00251.x

Coppi, A., Cabinian, M., Mirelman, D., and Sinnis, P. (2006). Antimalarial activity of allicin, a biologically active compound from garlic cloves. Antimicrob. Agents Chemother. 50, 1731-1737. doi: 10.1128/AAC.50.5.1731-1737.2006

Corral, M. J., Benito-Peña, E., Jiménez-Antón, M. D., Cuevas, L., Moreno-Bondi, M. C., and Alunda, J. M. (2016). Allicin induces calcium and mitochondrial dysregulation causing necrotic death in Leishmania. PLoS Negl. Trop. Dis. 10:e0004525. doi: 10.1371/journal.pntd.0004525

De Gianni, E., and Fimognari, C. (2015). Anticancer mechanism of sulfurcontaining compounds. Enzymes 37, 167-192. doi: 10.1016/bs.enz.2015. 05.003

D’Souza, S. P., Chavannavar, S. V., Kanchanashri, B., and Niveditha, S. B. (2017). Pharmaceutical perspectives of spices and condiments as alternative antimicrobial remedy. J. Evid. Based Complementary Altern. Med. 22, 1002-1010. doi: 10.1177/2156587217703214

DuBois, K. N., Abodeely, M., Sajid, M., Engel, J. C., and McKerrow, J. H. (2006). Giardia lamblia cysteine proteases. Parasitol. Res. 99, 313-316. doi: 10.1007/s00436-006-0149-4

Gallwitz, H., Bonse, S., Martínez-Cruz, A., Schlichting, I., Schumacher, K., and Krauth-Siegel, R. L. (1999). Ajoene is an inhibitor and subversive substrate of human glutathione reductase and Trypanosoma cruzi trypanothione reductase: crystallographic, kinetic, and spectroscopic studies. J. Med. Chem. 42, 363-372. doi: $10.1021 / \mathrm{jm} 980471 \mathrm{k}$

Gardner, T. B., and Hill, D. R. (2001). Treatment of giardiasis. Clin. Microbiol. Rev. 14, 114-128. doi: 10.1128/CMR.14.1.114-128.2001

Gargantini, P. R., Serradell, M. D. C., Ríos, D. N., Tenaglia, A. H., and Luján, H. D. (2016). Antigenic variation in the intestinal parasite Giardia lamblia. Curr. Opin. Microbiol. 32, 52-58. doi: 10.1016/j.mib.2016.04.017

Gupta, N., and Porter, T. D. (2001). Garlic and garlic-derived compounds inhibit human squalene monooxigenase. J. Nutr. 131, 1662-1667. doi: 10.1093/jn/131.6.1662

Harris, J. C., Plummer, S., Turner, M. P., and Lloyd, D. (2000). The microaerophilic flagellate Giardia intestinalis: Allium sativum (garlic) is an effective antigiardial. Microbiology 12, 3119-3127. doi: 10.1099/00221287-14612-3119

Keister, D. B. (1983). Axenic culture of Giardia lamblia in TYI-S-33 medium supplemented with bile. Trans. R. Soc. Trop. Med. Hyg. 77, 487-488. doi: 10.1016/0035-9203(83)90120-7

Lane, S., and Lloyd, D. (2002). Current trends in research into the waterborne parasite Giardia. Crit. Rev. Microbiol. 28, 123-147. doi: 10.1080/1040-840291046713

Lawson, L. D. (1996). "The composition and chemistry of garlic cloves and processed garlic," in Garlic: The Science and Therapeutic Applications of Allium sativum L. and Related Species, eds H. P. Koch and L. D. Lawson (Baltimore, MD: Williams \& Wilkins), 57.

Lawson, L. D., and Wang, Z. G. (1993). Pre-hepatic fate of the organosulfur compounds derived from garlic (Allium sativum). Planta Med. 59, A688-A689. doi: 10.1055/s-2006-959976

Liu, Y., Peterson, D. A., Kimura, H., and Schubert, D. (1997). Mechanism of cellular 3-(4,5-dimethylthiazol-2-yl)-2,5-diphenyltetrazolium bromide (MTT) reduction. J. Neurochem. 69, 581-593.

Martínez-Espinosa, R., Argüello-García, R., Saavedra, E., and Ortega-Pierres, G. (2015). Albendazole induces oxidative stress and DNA damage in the parasitic protozoan Giardia duodenalis. Front. Microbiol. 6:800. doi: $10.3389 /$ fmicb. 2015.00800

Millet, C. O., Lloyd, D., Williams, C., Williams, D., Evans, G., Saunders, R. A., et al. (2011). Effect of garlic and allium-derived products on the growth and metabolism of Spironucleus vortens. Exp. Parasitol. 127, 490-499. doi: 10.1016/j.exppara.2010.10.001

Milner, J. A. (2001). Mechanisms by which garlic and allyl sulfur compounds suppress carcinogen activation. Garlic and carcinogenesis. Adv. Exp. Med. Biol. 492, 69-81. doi: 10.1007/978-1-4615-1283-7_7

Moghadam, F. J., Navidifar, T., and Amin, M. (2014). Antibacterial activity of garlic (Allium sativum L.) on multi-drug resistant Helicobacter pylori isolated from gastric biopsies. Int. J. Enteric Pathog. 2:e16749. doi: 10.17795/ijep16749

Müller, A., Eller, J., Albrecht, F., Prochnow, P., Kuhlmann, K., Bandow, J. E., et al. (2016). Allicin induces thiol stress in bacteria through S-Allylmercapto modification of protein cysteines. J. Biol. Chem. 291, 11477-11490. doi: 10.1074/jbc.M115.702308

Northrop-Clewes, C. A., Rousham, E. K., Mascie-Taylor, C. N., and Lunn, P. G. (2001). Anthelmintic treatment of rural Bangladeshi children: effect on host physiology, growth, and biochemical status. Am. J. Clin. Nutr. 73, 53-60. doi: 10.1093/ajcn/73.1.53

Ortega-Pierres, G., Argüello-García, R., Laredo-Cisneros, M. S., Fonseca-Linán, R., Gómez-Mondragón, M., Flores-Benítez, D., et al. (2018). Giardipain-1, a protease Secreted by Giardia duodenalis trophozoites causes junctional, barrier and apoptotic damages in epithelial cell monolayers. Int. J. Parasitol. 48, 621-639. doi: 10.1016/j.ijpara.2018.01.006

Pinilla, C. M., Noreña, C. P., and Brandelli, A. (2017). Development and characterization of phosphatidylcholine nanovesicles, containing garlic extract, with antilisterial activity in milk. Food Chem. 220, 470-476. doi: 10.1016/j.foodchem.2016.10.027

Pinto, J. T., Krasnikov, B. F., and Cooper, A. J. L. (2006). Redox-sensitive proteins are potential targets of garlic-derived mercaptocysteine derivatives. J. Nutr. 136, 835S-841S. doi: 10.1093/jn/136.3.835S

Rabinkov, A., Miron, T., Konstantinovski, L., Wilchek, M., Mirelman, D., and Weiner, L. (1998). The mode of action of allicin: trapping of radicals and interaction with thiol containing proteins. Biochim. Biophys. Acta 1379, 233-244. doi: 10.1016/S0304-4165(97)00104-9

Redlinger, T., Corella-Barud, V., Graham, J., Galindo, A., Avitia, R., and Cárdenas, V. (2002). Hyperendemic Cryptosporidium and Giardia in households lacking municipal sewer and water on the United States-Mexico border. Am. J. Trop. Med. Hyg. 66, 794-798. doi: 10.4269/ajtmh.2002.66.794

Reyes-Vivas, H., Diaz, A., Peon, J., Mendoza-Hernandez, G., HernandezAlcantara, G., De la Mora-De la Mora, I., et al. (2007). Disulfide bridges in the mesophilic triosephosphate isomerase from Giardia lamblia are related to oligomerization and activity. J. Mol Biol. 365, 752-763. doi: 10.1016/j.jmb.2006.10.053

Salama, A. A., AbouLaila, M., Terkawi, M. A., Mousa, A., El-Sify, A., Allaam, M., et al. (2014). Inhibitory effect of allicin on the growth of Babesia and Theileria equi parasites. Parasitol. Res. 113, 275-283. doi: 10.1007/s00436-013-3654-2

Schmatz, D. M. (1997). The mannitol cycle in Eimeria. Parasitology 114(Suppl.), S81-S89.

Seddiek, S. H. A., El-Shorbagy, M. M., Khater, H. F., and Ali, A. M. (2014). The antitrichomonal efficacy of garlic and metronidazole against Trichomonas gallinae infecting domestic pigeons. Parasitol. Res. 113, 1319-1329 doi: 10.1007/s00436-014-3771-6

Soffar, S. A., and Mokhtar, G. M. (1991). Evaluation of the antiparasitic effect of aqueous garlic (Allium sativum) extract in Hymenolepiasis nana and giardiasis. J. Egypt Soc. Parasitol. 21, 497-502. 
Soumya, R. S., Sherin, S., Raghu, K. G., and Abraham, A. (2017). Allicin functionalized locust bean gum nanoparticles for improved therapeutic efficacy: An in silico, In vitro and in vivo approach. Int. J. Biol. Macromol. 109, 740-747. doi: 10.1016/j.ijbiomac.2017.11.065

Waag, T., Gelhaus, C., Rath, J., Stich, A., Leippe, M., and Schirmeister, T. (2010). Allicin and derivates are cysteine protease inhibitors with antiparasitic activity. Bioorg. Med. Chem. Lett. 20, 5541-5543. doi: 10.1016/j.bmcl.2010.07.062

WHO (2006). The World Health Report 1996. Fighting Disease Fostering Development. World Health Organization. Available online at: http://www. who.int/whr/1996/en/

Williams, C. F., Yarlett, N., Aon, M. A., and Lloyd, D. (2014). Antioxidant defences of Spironucleus vortens: glutathione is the major non-protein thiol. Mol. Biochem. Parasitol. 196, 45-52. doi: 10.1016/j.molbiopara.2014.07.010

Yang, C. S., Chhabra, S. K., Hong, J. Y., and Smith, T. J. (2001). Mechanisms of inhibition of chemical toxicity and carcinogenesis by diallyl sulfide
(DAS) and related compounds from garlic. J. Nutr. 131, 1041S-1045S. doi: $10.1093 / \mathrm{jn} / 131.3 .1041 \mathrm{~S}$

Conflict of Interest Statement: The authors declare that the research was conducted in the absence of any commercial or financial relationships that could be construed as a potential conflict of interest.

Copyright (๑ 2018 Argüello-García, de la Vega-Arnaud, Loredo-Rodríguez, MejíaCorona, Melgarejo-Trejo, Espinoza-Contreras, Fonseca-Liñán, González-Robles Pérez-Hernández and Ortega-Pierres. This is an open-access article distributed under the terms of the Creative Commons Attribution License (CC BY). The use, distribution or reproduction in other forums is permitted, provided the original author(s) and the copyright owner(s) are credited and that the original publication in this journal is cited, in accordance with accepted academic practice. No use, distribution or reproduction is permitted which does not comply with these terms. 